\title{
Gas/liquid flow behaviours in a downward section of large diameter vertical serpentine pipes
}

\author{
Almabrok A. Almabrok ${ }^{\mathrm{a}, \mathrm{b}}$, Aliyu M. Aliyu ${ }^{\mathrm{a}}$, Liyun Lao $^{\mathrm{a}, 1}$, and Hoi Yeung ${ }^{\mathrm{a}}$ \\ a Oil and Gas Engineering Centre, School of Energy, Environment and Agrifood, Cranfield University, \\ Cranfield, Bedfordshire, MK43 OAL, United Kingdom. \\ $b$ Department of Petroleum Engineering, Faculty of Engineering, Sirte University, Libya.
}

PII: S0301-9322(15)00210-4

DOI: 10.1016/j.ijmultiphaseflow.2015.09.012

Reference: IJMF 2288

To appear in: International Journal of Multiphase Flow

Received date: 24 April 2015

Revised date: 22 August 2015

Accepted date: 25 September 2015

Please cite this article as: Almabrok A. Almabrok , Aliyu M. Aliyu , Liyun Lao , Hoi Yeung , Gas/liquid flow behaviours in a downward section of large diameter vertical serpentine pipes, International Journal of Multiphase Flow (2015), doi: 10.1016/j.ijmultiphaseflow.2015.09.012 This is a PDF file of an unedited manuscript that has been accepted for publication. The manuscript will undergo copyediting, typesetting, and review of the resulting proof before it is published in its final form. Please note that during the production process errors may be discovered which could affect the content, and all legal disclaimers that apply to the journal pertain.

1 Corresponding author. Tel.:+44 1234 754696; Fax: +44 1234 754685. E-mail address: I.lao@cranfield.ac.uk (L.Lao) 


\title{
Gas/liquid flow behaviours in a downward section of large diameter vertical serpentine pipes
}

\author{
Almabrok A. Almabrok ${ }^{\mathrm{a}, \mathrm{b}}$, Aliyu M. Aliyu ${ }^{\mathrm{a}}$, Liyun Lao $^{\mathrm{a}, 2}$, and Hoi Yeung ${ }^{\mathrm{a}}$ \\ a Oil and Gas Engineering Centre, School of Energy, Environment and Agrifood, Cranfield University, \\ Cranfield, Bedfordshire, MK43 OAL, United Kingdom. \\ $b$ Department of Petroleum Engineering, Faculty of Engineering, Sirte University, Libya.
}

\begin{abstract}
An experimental study on air/water flow behaviours in a $101.6 \mathrm{~mm}$ i.d. vertical pipe with a serpentine configuration is presented. The experiments are conducted for superficial gas and liquid velocities ranging from 0.15 to $30 \mathrm{~m} / \mathrm{s}$ and 0.07 to $1.5 \mathrm{~m} / \mathrm{s}$, respectively. The bend effects on the flow behaviours are significantly reduced when the flow reaches an axial distance of 30 pipe diameters or more from the upstream bend. The mean film thickness data from this study has been used to compare with the predicted data using several falling film correlations and theoretical models. It was observed that the large pipe data exhibits different tendencies and this manifests in the difference in slope when the dimensionless film thickness is plotted as a power law function of the liquid film Reynolds number.
\end{abstract}

Keywords: Downward gas/liquid flow; Flow development; Bend; Liquid film thickness; Void fraction.

\section{Introduction}

Upward and downward pipes connected together by return bends are common in heat exchange facilities which are widely used in space heating, refrigeration, power stations, chemical plants, and petroleum refineries. Typically the flow in such pipes can be single phase (liquid or gas) flow or liquid/gas two-phase flow depending on the fluid properties and operation conditions of the facilities. Amongst these flows it is the gas/liquid two-phase flow that imposes the most challenging problems related to the design and operation of the heat exchange facilities. For example maldistribution of liquid film on the pipe wall could cause some part of the pipe locally overheated, furthermore may

1 Corresponding author. Tel.:+44 1234 754696; Fax: +44 1234 754685. E-mail address: l.lao@cranfield.ac.uk (L.Lao) 
lead to undesirable results in the facility. Indeed as deformable interfacial structure is involved, gas/liquid phase distribution is very complex in nature, thus the related heat transfer regime is also extremely complex. The two phase flow regime occurring at different sections of a heated vertical channel, as noted by Hewitt \& Hall-Taylor (1970), could be varied from bubbly, slug, churn, annular to mist flows. When two-phase fluid flows through the bend, the centrifugal force generated could cause a flow maldistribution due to the significant density difference between the liquid and gas phases creating local dry spots. Obviously the effect of the centrifugal force on the phase distribution will happen not only in the bend, but also in the straight channel after the bend.

There are a number of published studies concerned the effects of return bends on the gas/liquid flow behaviours in the bends and pipes. The majority of these studies were mainly on pipes of 1 inch or similar pipe sizes. For example, Alves (1954), Hills (1973), and Anderson \& Hills (1974) presented studies on liquid film behaviours in return bends of 1 inch pipe diameter for different orientations. Oshinowo \& Charles (1974) also investigated the effect of return bend on the void fraction in a 1 inch vertical serpentine pipe. They applied the balance between centrifugal and gravitational forces acting on the phases in the bend to explain the phase distributions. Usui et al. (1980, 1981 \& 1983) used a modified Froude number as criteria to decide the liquid phase distribution tendency in flows of three different return bends, i.e. upward and downward flows in a C-shaped bend in vertical plane, and flows in an inverted U-bend. Poulson (1991) also studied the mass transfer in a horizontal return bend with upward flows and concluded that the mass transfer at the bends relative to straight sections increases with superficial gas velocities and is constant at low superficial liquid velocities. Studies on the bend effect on two-phase flows were also extended to much smaller or larger sizes pipelines. Wang et al. (2003 \& 2008), and Wang et al. (2004) investigated the twophase flow in small pipes. The pipe sizes of their work were down to $3 \mathrm{~mm}$, where the surface tension played a much more significant role than in larger size pipes. On the other 
hand, Hoang and Davis (1984) reported experimental results of void fraction in froth flow in a 2 inch diameter U-bend using needle probes. Chong et al. (2005) calculated the liquid film in $150 \mathrm{~mm}$ internal diameter (i.d.) of U-bend and inverted U-bend which was used to join vertical straight pipes to form a serpentine pipeline. More recently, Abdulkadir et al. (2012) reported an experimental study of churn-annular flow behaviour and film fraction of airwater mixture through a $127 \mathrm{~mm}$ i.d. inverted U-bend. They measured the film fraction before, within and after the bend and noted that the film break up occurs at $45^{\circ}$ due to gravity drainage.

Another issue related to the behaviours of the two-phase flow after a bend is their developing nature, due to the residual bend effect. As a major concern for the heat exchange facility's operation is closely related to liquid film distribution on the pipe wall surface, thus the knowledge of the development related to annular flow regime is particularly important.

The development of gas/liquid annular flows has long been noted by a number of researchers, but so far most of them were on the upward flows. Gill et al. (1963) and Gill \& Hewitt (1966) measured a film thickness and entrained liquid flow rate at different axial positions which ranged between 5-160 pipe diameters, downstream of gas/liquid injector, in a $31.8 \mathrm{~mm}$ diameter pipe. They also compared the results from different liquid injectors, namely porous sinter and axial jet injectors, and found that the liquid film thickness development in vertical annular flow largely depends on the inlet geometry when a low liquid mass flux is applied. Brown et al. (1975) extended the investigation above and conducted measurements of the pressure gradient and the entrainment rate obtained at distances up to 560 tube diameters from the inlet. Similarly they also used porous sinter and centre jet devices. They found that the differences between the two inlet devices persisted even at 550 pipe diameters indicating that the flow was not yet fully developed. Wolf et al. (2001) reported a comprehensive study on the development of air-water upward annular flow, giving local values of the pressure 
gradient, film thickness, wall shear stress, film flow rate, disturbance wave velocity and frequency. Hawkes et al. (2000) reported experiments to study the development of wispy annular flow with air and water mass fluxes of 70-210 $\mathrm{kg} \mathrm{m}^{-2} \mathrm{~s}^{-1}$ and $120-1030 \mathrm{~kg} \mathrm{~m}^{-2} \mathrm{~s}^{-1}$, respectively. Lao et al. (2004) extended the flow conditions up to a liquid mass flux of 1200 $\mathrm{kg} \mathrm{m}^{-2} \mathrm{~s}^{-1}$ using different liquid inlet devices. It was concluded that at a high liquid mass flux, the effect of injecting on the film thickness of the wall was less significant than that at low liquid mass flux. More recently, Hazuku et al. (2008) reported the measurements of the interfacial wave structure development of upward annular two-phase flow in a vertical pipe using a laser focus displacement meter (LFD). Experiments were conducted using a $3 \mathrm{~m}$ long, $11 \mathrm{~mm}$ pipe diameter, with Reynolds numbers ranging from 31,800 to 98,300 for the gas phase and 1050 to 9430 for the liquid phase. They found that the flow development persisted until the end of the pipe. Abdulkadir et al. (2012) measured film thicknesses in straight sections before and after an inverted U-bend and noted that the liquid film thickness develops within and after the bend.

The literature study above shows that the behaviours of gas/liquid two-phase flow after a $180^{\circ}$ bend can be significantly influenced by the bend. While such behaviours have in the past been extensively studied in smaller channels, literature is bereft of studies for gas/liquid two-phase flows in large pipes (with internal diameter $>100 \mathrm{~mm}$ ), even more so for downwards flows, coupled with bend effects. Smith et al. (2012) and Schlegel et al. (2012) have noted that in boiling water reactors where the pipes are large diameter pipes, fundamental changes to the flow configuration, and as such small channel descriptions may not apply. For example classic bullet-shaped Taylor bubbles cannot be sustained in large diameter pipes and flow regime transition is affected right through to annular, and annularmist flows. Pickering et al. (2001) have stated the tenuous nature of extrapolating small to large scale multiphase models in oil and gas pipeline flow. This work therefore presents new 
gas/liquid two-phase flow experimental data in a large diameter $(101.6 \mathrm{~mm})$ tube and shows the flow behaviours in a large pipe after a bend.

An experimental investigation has been carried out on upward and downward vertical pipes with $180^{\circ}$ bends to study gas/liquid two-phase flow behaviours in pipes with serpentine configuration. Instrumentation, including film thickness probes and capacitance wire mesh sensors (WMS) are used for this study. The former are employed to obtain circumferential profiles of the liquid film thickness at different axial positions along the downward and upward sections of the Serpent rig. The latter is also installed at top, middle and bottom locations of both sections of the test facility in order to identify the void fraction distributions. Further features such as flow patterns and liquid film wave structures are identified by examining the time traces and probability density function (PDF) from the WMS and liquid film sensors. All measurements are conducted for superficial air and water velocities ranging from 0.15 to $30 \mathrm{~m} / \mathrm{s}$ and 0.07 to $1.5 \mathrm{~m} / \mathrm{s}$, respectively.

This paper mainly summarises and reports the results with respect to the downward flows downstream of a $180^{\circ}$ bend. The results with respect to the upward flows after a $180^{\circ}$ bend are reported in a separate paper.

\section{Experimental Setup}

\subsection{Test rig}

A purpose-built rig, the Serpent test facility, is designed and set up in the Flow Laboratory at Cranfield University. The rig is schematically shown in Figure 1, which comprises of the fluid supply and metering section, the test section and the fluid separation section.

Air is supplied from a bank of two compressors, GA75 and GA55, connected in parallel. A maximum air flow rate of $1200 \mathrm{Sm}^{3} / \mathrm{h}$ can be supplied. The air from the compressors is accumulated in an air receiver with a capacity of $8 \mathrm{~m}^{3}$ to reduce the pressure fluctuation from the compressor. Although not shown in the figure, the air from the receiver passes through a 
bank of three filters and then through a cooler where debris and moisture are stripped from the air before it is metered. The flow rate of the air is regulated by two automated valves (i.e. VC301 and VC302) and measured by one of a bank of two Rosemount Mass Probar flow meters (i.e. FA1 and FA2). FA1 is used to measure an air flow rate from 0 to150 $\mathrm{Sm}^{3} / \mathrm{h}$, and FA2 for an air flow rate of above $150 \mathrm{Sm}^{3} / \mathrm{h}$. Water is supplied from a $1.2 \mathrm{~m}^{3}$ capacity water tank. The water is pumped to the flow loop by a Grundfos CRE3-26 speed variable pump which has a maximum duty of 10 1/s at 6 barg. The flow rate of the water can be regulated by adjusting the pump speed, and/or a manual bypass valve VW2 between the pump outlet and the water tank. The water flow rate is metered by a $100 \mathrm{~mm} \mathrm{ABB}$ electro-magnetic flow meter MMSG-Special.

The air and water are mixed using a Tee joint before entering the test section. The test section consists of a flow loop of $101.6 \mathrm{~mm}$ i.d. and about $20.0 \mathrm{~m}$ long in total. It includes four vertical sections connected by three $180^{\circ}$ bends (bend 1, 2 and 3). Each bend, with a radius of $203 \mathrm{~mm}$, is made of cast Perspex. It is first machined using CNC milling technique in two halves, inner surface polished and then glued together. The wall roughness of the bends is estimated around $5 \times 10^{-6} \mathrm{~m}$. The middle two vertical sections, one downward and one upward, each having a $6.0 \mathrm{~m}$ of straight pipe, are the test sections. In each section, three measurement and visual observation (MV) stations are installed. Each of these stations comprises of a liquid film sensor spool which is used to measure water film thickness at four different circumferential locations, and a clear section for the visual observation of the flow. A WMS spool can be added into the station if the void fraction cross-sectional distribution at the location is to be measured. This spool is placed at the downstream of the liquid film sensor spool, in order not to disturb the measurement of liquid film thickness. More details about the liquid film sensor and WMS spools are described in section 2.2 below. Six GE PMP4070 pressure transducers, P1-P6, are also installed to measure the pressure along the 
downward section. In addition two PT100 temperature sensors, PT1 and PT2, are used to measure the water and air/water mixture temperatures, respectively. The locations of the measurement and visual observation stations, pressure sensors and temperature sensors along the test section are presented in Table 1 below. Some of the key specifications of the instrumentation in the Serpent rig are shown in the appendix of this paper.

The air and water mixture are separated in a vented tank which is covered with a lid with outlets. Air is vented into the atmosphere via the outlets while, the water driven by gravity flows back to the water tank via a $150 \mathrm{~mm}$ i.d. pipe. The outlets have filters installed in order to reduce the amount of mist discharging into the atmosphere.

\subsection{Film thickness sensor spools}

\subsubsection{Sensor design}

The film thickness probe spool is shown in Figure 2 (a) and schematically in Figure 2 (b). The spool consists of four film conductivity sensors which are evenly distributed circumferentially to measure the circumferencial distribution of the liquid film thickness at the location where the spool is installed. As shown in Figure 2 (c) the sensing part of the conductivity film thickness probe comprises a $10 \mathrm{~mm}$ diameter stainless steel rod and a stainless steel sleeve (18 mm outer diameter by $2 \mathrm{~mm}$ wall) arranged concentrically. Between them is a $2 \mathrm{~mm}$ thick insulation layer. The end of the sensor is flush with the inner surface of the spool. Each conductor is electrically in contact with the liquid film when the liquid film flows over them, so a conductive bridge is formed. The conductivity between the two conductors is expected to change with the thickness of the water film.

\subsubsection{Film thickness probe calibration and repeatability check}

For conductivity film thickness probes, it is well accepted that the normalised output, i.e. ratio of output voltage to full scale voltage, should be used calibration and measurements, as this is helpful to eliminate or mitigate the measurement errors caused by the draft of liquid 
conductivity or the electronics due to environmental factors such as temperature. The calibration was carried out by using acrylic blocks of different diameters (Figure 3 (a)) inserted into the probe spool coaxially to form a liquid layer with known thickness. Figure 3 (b) shows a typical calibration curve - a plot of the measured film thickness against normalised voltage output corresponding to that used at the top position of the downward flowing section of the flow loop. Twenty four normalised calibration curves were obtained during the static experiments.

The repeatability of the liquid film thickness probes were also checked. Three repeated runs were carried out for gas superficial velocities of 1.44, 3.02, 4.60, 6.20, 9.38, 12.47, 18.39, 23.66 and $28.87 \mathrm{~m} / \mathrm{s}$, with a constant liquid superficial velocity of $0.1 \mathrm{~m} / \mathrm{s}$. Figure 3 (c) illustrates the results achieved from one of the film probes and the discrepancy was around $0.1 \mathrm{~mm}$ for the downward annular flows over all gas velocities.

In order to further correct the temperature drift errors in film thickness measurement, in addition to the use the normalised outputs of the film thickness sensors, a temperature correction coefficient for the sensors is also identified and used. The correction is applied to a temperature range of $10-35^{\circ} \mathrm{C}$, which covers the two-phase mixture temperature range $15-22$ ${ }^{\circ} \mathrm{C}$ in which the tests are performed. During a test both the water and water/air mixture temperatures were logged so temperature compensation was able to be implemented in order to obtain film thickness values during the off-line data processing.

\subsection{Wire mesh sensor (WMS)}

A $32 \times 32$ WMS, as shown in Figure 4 (a), is used for air-water void sectional distribution measurement at different locations along the pipeline. The sensor, associated electronics and data processing software are supplied by Helmholtz-Zentrum Dresden-Rossendorf, Germany. The method of phase fraction distribution measurement in air/water flows using similar WMS systems has been validated by a number of studies, for example Prasser et al. 
(2007), and Da Silva et al. (2010). In the sensor spool, wire electrodes are stretched across the flow cross-sectional area with the two sets of wire electrodes being perpendicular to each other. One set acts as a sender while the other acts as a receiver. The wire mesh sensor electronics measures the local permittivity of the fluid in the gaps of each crossing point by successively applying an excitation voltage to each one of the sender electrodes while keeping all other sender electrodes at ground potential and measuring, respectively, the AC electrical current flow to all receiver electrodes synchronously. Based on these measurements the cross-sectional fluid distribution across the pipe the sensor is able to be estimated. More details about WMS can be found in Da Silva et al. (2007). For the sensor used in this study, the separation between the sender and receiver planes of wires is $2.5 \mathrm{~mm}$. The spacing between two wires in parallel is $3.2 \mathrm{~mm}$. A sampling rate of 1000 frames cross-sectional images per second is used for the measurement.

On the straight upwards section of the Serpent rig, void fraction measurements by other methods were compared with the time and cross-sectionally averaged void fraction values obtained from the WMS. The upwards section was chosen as the flow regimes in this section cover different vertical flow regimes as the gas flow rate is increased. In the validation tests, a low liquid superficial velocity of $0.1 \mathrm{~m} / \mathrm{s}$ was used, while the air velocity varied in the range of $0.15-30.0 \mathrm{~m} / \mathrm{s}$. At an air velocity up to $6.0 \mathrm{~m} / \mathrm{s}$, the flow regimes are bubbly, slug and churn flows. In these flows, the void fraction obtained from the differential pressure $\Delta P$ using the pressure transducers $\mathrm{P}_{4}$ and $\mathrm{P}_{5}$ were compared with the WMS values obtained at the measurement and visual observation station MV22, which is the middle point between the locations of pressure transducers $\mathrm{P}_{4}$ and $\mathrm{P}_{5}$ on the pipe. The distance $L$ between the two transducers is $4.1 \mathrm{~m}$. On the assumption that the frictional pressure drop is negligible the $\varepsilon$, i.e. the average void fraction at the WMS position can be calculated from the equation:

$$
\varepsilon=1-\frac{\Delta P / L}{g\left(\rho_{L}-\rho_{g}\right)}
$$


where $g$ is the gravitational acceleration, $\rho_{L}$ and $\rho_{G}$ are the densities of water and air respectively.

For the superficial air velocity larger than $10.0 \mathrm{~m} / \mathrm{s}$, which results in an annular flow regime, film thickness (FT) measurements were used to obtain the void fraction by the equation:

$$
\varepsilon=\frac{4\left(D t-t^{2}\right)}{D^{2}}
$$

where $t$ is film thickness, $D$ the internal diameter of the pipe. Apparently here liquid entrainment in the gas core was ignored in the calculation of the void fraction.

Figure 4 (b) shows the comparison of the WMS void fractions with those obtained using Equations 1 and 2 . As can be seen, in the low void fractions range $(<20 \%)$, the WMS is likely underestimate the void fraction as much as about $12 \%$ in a relative error. While in the range of the void fraction between $20 \%$ to $50 \%$, the WMS void fractions can be up to $20 \%$ higher in comparing with the referenced void fractions by a relative term. In the upper half range of the void fraction( $>50 \%)$, the differences between the referenced and WMS void fractions are much smaller. However it is worth to note the referenced void fraction itself is only an approximation of void fraction as the frictional pressure drop for DP method, or the liquid entrainment for film thickness method, was ignored. Nonetheless the relative uncertainty of WMS measurement for large void fraction (which is the main concern of this study) is estimated within $\pm 10 \%$.

\subsection{Positioning of liquid film probe and WMS in the test section}

The positioning of the film sensors around a circumference are shown in Figure 5 (a). The $90^{\circ}$ position corresponds to the outside curvature of the upstream bend, and $270^{\circ}$ to the inside of the upstream bend. The film sensors C1-C4 are used for downward flows and the sensors C5-C8 are used for upward flows. 
Figure 5 (b) shows that the sender wires are in the $0^{\circ}-180^{\circ}$ direction and the receiver wires are in the $90^{\circ}-270^{\circ}$ direction. By this arrangement the chordal distribution of the void fraction along both $0^{\circ}-180^{\circ}$ and $90^{\circ}-270^{\circ}$ directions can be conveniently obtained from the crosssectional distribution of the void fraction, which is used to assess the extent of the phase distribution asymmetry over a cross-section at the measuring position of the pipe, thus to judge the influence of the upstream bend on the phase distribution at each axial position along the pipe.

\subsection{Test procedures}

Prior to starting the tests, the test section is first emptied and blown dry. The air flow is then stopped to record the zero points of the instrumentation. The rig is then filled with water to record full scale output of liquid film sensors and WMS, which will be used for the normalisation of the outputs from the sensors and the WMS, respectively. During the experiments, for each test run the water flow rate is adjusted to a predetermined value before air is introduced to the test section. The water flow rate is monitored and adjusted to keep it at the predetermined value while the air flow is slowly increased to the desired value. The data will not be logged until both the water and air flow rates become stable. The record period for each test run is three minutes for the liquid film and pressure sensors, and one minute for the WMS. In order to ensure the quality of the data, zero points of the instrumentation are checked regularly, at least twice a day during testing.

A LabView program is developed for recording the pressures, film thickness and fluid temperature. The sampling rate is $100 \mathrm{~Hz}$, which is fast enough to capture the fluctuation of these parameters in the test. The LabView system also provides an on-line view of the time traces of these parameters.

The test matrix and its flow conditions are presented in the appendix of the paper. 


\section{Experimental Results}

\subsection{Flow regime development in downward flow}

The data of cross-sectional phase fraction distributions collected using WMS at the top, middle and bottom positions of the downward section show the flow regime and its development along the pipe.

Figure 6 shows axial slice images $(\mathrm{X}$ and $\mathrm{Y})$ and cross-section images $(\mathrm{Z})$ phase distribution at different axial positions (i.e. top, middle and bottom positions, corresponding to 5, 30, and 46 pipe diameters respectively,) and different flow conditions in the downward section. The data used for the figure are obtained for different superficial air velocities $\left(U_{s g}\right)$ while the superficial water velocity $\left(U_{s l}\right)$ is kept at $1.0 \mathrm{~m} / \mathrm{s}$. The images are reconstructed from the WMS data. Image $X$ is obtained by stacking cross-section images and then being axially sliced along $0^{\circ}-180^{\circ}$ direction. Likewise image $\mathrm{Y}$ along $90^{\circ}-270^{\circ}$ direction (refer to Figure 5 (b)). In order to give near reality geometries of phase structures in the pipe, the number of the cross-section images $N$ used to reconstruct the axial slice images is given by $N=f_{s} L_{p} / U_{m}$, where $f_{s}$ is the WMS system frame rate, i.e. $1000 \mathrm{fps} ; L_{p}$ is the pipe section length represented by the axial sliced images, i.e. $1000 \mathrm{~mm}$ in this study; and $U_{m}$ is the mixture velocity at the respective flow conditions. In the images, colour varies from blue to red representing the void fraction changing from 0 (i.e. air) to $100 \%$ (i.e. water). As can be seen from the figure, for a superficial air velocity of $0.15 \mathrm{~m} / \mathrm{s}$, the flow is aerated however with a significant amount of water in the form of wisps entrained into the flow at the top position. These wisps are like objects with long tails occupied some parts of the pipe. The crosssection images clearly show that, the liquid phase has a tendency towards the circumferential position of $90^{\circ}$, corresponding to the outside curvature of the upstream top bend (bend 1). However, the flow at the middle position becomes liquid phase dominated and gas phase is not continuous anymore; the cross-section image show that, the cross-sectional phase 
distribution at the middle position is less asymmetric with respect to the pipe axis in comparing with its top position counterpart. At the bottom position the axial slice images show that, the large bubbles break down into small bubbles, and are evenly distributed at various places of the cross-section of the pipe, resulting in a bubbly flow formation; meanwhile the cross-section image shows that the cross-sectional phase distribution is fairly homogeneous.

At the top position as the $U_{s g}$ increases the wisps disappear and the flow regime becomes a typical annular flow. For all air flow rates in the figure, the liquid phase fraction at the circumferential position of $90^{\circ}$, corresponding to the outside curvature of the upstream top bend (bend 1) is much larger than the other positions (i.e. $0^{\circ}, 180^{\circ}$ and $270^{\circ}$ ). This phenomenon should be mainly due to the centrifugal force in the upstream bend.

At the middle position, the images show that, the flow regimes are significantly different from that at the top position when superficial air velocities are low. For all superficial air velocities, the cross-section images show that, the cross-sectional phase distributions are much less asymmetric with respect to the pipe axis in comparison with their top position counterparts. This is particularly obvious for $U_{s g}=18.50 \mathrm{~m} / \mathrm{s}$.

At the bottom position, when the $U_{s g}$ increases from 0.15 to $0.52 \mathrm{~m} / \mathrm{s}$, large bubbles are formed as a consequence of coalescence of small bubbles in which they fill most of the pipe cross-section. At higher superficial air velocities $\left(U_{s g}=1.02\right.$ and $\left.2.70 \mathrm{~m} / \mathrm{s}\right)$, it is observed that an intermittent flow regime is created. The flow regime achieved at a higher superficial air velocity $\left(U_{s g}=18.50 \mathrm{~m} / \mathrm{s}\right)$ is an annular flow. The cross-sectional phase distribution is fairly symmetric with respect to the pipe axis in comparing with their counterparts at the top and middle positions. 
Flow regimes, its developments and asymmetries of cross-sectional phase distribution in the downward section are also confirmed by examining the void fraction time traces, their probability density functions (PDFs) and chordal void fraction distribution, respectively, obtained from the WMS data. The void fraction PDF method is a widely recognised method, which was used by many researchers for decades, for example, Kelessidis and Dukler (1989), and, more recently Omebere-Iyari et al. (2008). Figure 7 shows the time traces of the void fraction and the respective PDFs obtained locally at the top, middle and bottom positions of the downward section, at a fixed superficial water velocity $\left(U_{s l}=1.0 \mathrm{~m} / \mathrm{s}\right)$ and a superficial air velocity $\left(U_{s g}\right)$ ranged from 0.15 to $9.80 \mathrm{~m} / \mathrm{s}$. The time traces are obtained by the cross sectionally averaged WMS void fraction data acquired at a rate of $1000 \mathrm{~Hz}$. As can be seen, at $U_{s g}$ of $0.15 \mathrm{~m} / \mathrm{s}$, the time trace at the top position presents oscillations in a period of $\sim 10 \mathrm{~s}$. It is different from those obtained at the middle and bottom positions. The PDF of the time trace related to the top position has a feature of double peaks, which suggests the flow regime is an intermittent one. The PDFs related to middle and bottom positions are single peak with a much lower mean value of the void fraction (about 0.1 ), suggesting the flow regime is similar to dispersed bubbly flow. However, it is also noted that the bubbly flow pattern is mixed with periodic large air pockets hence the flow is still an oscillatory one. A visual observation of the flow behaviour inside bend 2 which is at the bottom, downstream of the downward straight section, suggests that liquid can periodically blocks the bottom section when the air flow rate is low. Except those entrained air bubbles, the blockage will stop air pass through until the air is accumulated and the sufficient energy being built up to overcome this liquid blockage. Each of the cycles is also about 10 seconds long. The coincidence of periods may suggest that, the above mentioned flow pattern is related to both the flow conditions and the pipeline's vertical serpentine geometry. The flow regime is similar to that which occurred in an inverted U-type pipeline reported by Golan \& Stenning (1969). Figure 7 
also shows that, the oscillatory flow regime also occurs when the $U_{s g}$ is $1.02 \mathrm{~m} / \mathrm{s}$, however the amplitude and period of the oscillation decreases as the $U_{s g}$ increased. When the $U_{s g}$ increased to $9.80 \mathrm{~m} / \mathrm{s}$ or higher, the oscillatory flow regime disappears and the PDFs of the void fraction time traces at the top, middle and bottom positions have only one peak. However, the peak width of the PDF is decreased from the top towards the bottom, which indicates the cross-sectional void fraction less fluctuated.

The flow regime maps for the top, middle and bottom positions are presented in Figure 8 (a), (b) and (c) for various superficial air and water velocities. It can be noted from Figure 8 that the bubbly, intermittent and annular flows are present for all three axial positions. The dominant flow regime in the downward section is annular flow. The boundary between the bubbly flow region and intermittent flow region in the flow regime map for the top position corresponds to a higher liquid and lower gas velocity than that at the middle and bottom positions. However, the boundary between the intermittent flow region and the annular flow region in the flow regime maps related to all positions are similar. Overall the flow maps for both middle and bottom positions are very similar. This suggests that the $180^{\circ}$ top bend has a major influence on the flow characteristics at the top position. The influence is much reduced when the flow reaches the middle and bottom positions.

Barnea et al. (1982) attempted to predict the gas/liquid flow regimes in downward pipes. They argued that the transition from bubbly flow to intermittent flow will occur when the bubble size is sufficiently large so that bubble coalescence occurs. They proposed an equation to determine the flow condition of the transition by using pipe diameter and fluid properties. They also suggested that the transition between intermittent flow and annular flow will happen when the liquid void fraction is larger than 0.65 . The flow regime maps obtained from this study are compared with that predicted by Barnea et al. (1982) and Usui (1989). 
Figure 9 shows the comparison between the flow regime map at the middle position of the downward section, with the predictions of Barnea et al. and Usui. It is noted that, in both

cases, the boundary between the bubbly flow region and intermittent flow region in the map of the middle position matches the predicted boundaries fairly well, though Barnea et al. slightly over-estimated the liquid velocity and Usui slightly under-predicts the gas velocity. However, for the boundary between the intermittent flow region and annular flow region, both Barnea et al.'s and Usui's criteria slightly over-estimate the liquid velocity and significantly under-estimate the gas velocity at which the transition occurs. This perhaps suggests that the criteria for flow regime transition need modifying when being applied to downward flows in large diameter pipes.

\subsection{Void fraction development in downward flow}

The effects of $180^{\circ}$ on the cross-sectional void fraction distributions at three positions of the downward vertical pipe are also examined. As shown in Figure 10 (a), at superficial water velocities of 1.0 and $1.5 \mathrm{~m} / \mathrm{s}$ the mean void fraction values related to the top position increase very steeply when the superficial air velocities increased from 0.15 to $2.0 \mathrm{~m} / \mathrm{s}$. A similar tendency is also observed at the middle and bottom positions, as presented in Figure 10 (b) and (c), however the curves of mean void fraction against the air velocity are notably less steep than that at the top position.

In order to address the void fraction development along the pipe, the data above is also presented as the void fraction ratio against axial distance (i.e. 5D, 30D or 46D after the bend 1), as shown in Figure 11. Here the void fraction ratio at an axial position is defined as the ratio of the void fraction at that position to that of the bottom position, i.e. 46D after bend 1 . By this at any flow condition the void fraction ratio at the position of $46 \mathrm{D}$ is unity. It is observed that, in Figure 11 (a), with a superficial water velocity of $0.07 \mathrm{~m} / \mathrm{s}$, at any air 
velocity tested, the void fraction ratios of the three positions are close to unity. A similar feature can also be found in Figure 11 (b) and (c) for superficial liquid velocities of 0.2 and $0.48 \mathrm{~m} / \mathrm{s}$, and some of the flow conditions presented in Figure 11 (d), (e) and (f) for superficial water velocities of $0.7,1.0$ and $1.5 \mathrm{~m} / \mathrm{s}$, respectively. In these cases the void fraction shows an insignificant variation against the axial position at lower water flow rates. Indeed at these flow conditions an annular flow regime is well formed in the whole downward pipe section, in which the flow development is manifested via liquid film and liquid entrainment rather than void fraction.

However, when flow regimes other than annular flow are involved, a significant void fraction decrease occurs when the fluids are flowing down, implying the local air velocity is getting significantly higher. In some flow conditions the void fraction development leads to a flow regime transition, e.g. in the case of $U_{s l}=1.0 \mathrm{~m} / \mathrm{s}$ and $U_{s g}=0.15 \mathrm{~m} / \mathrm{s}$ (Figure $11(\mathrm{e})$ ) where the flow regime is intermittent at the top position however it becomes bubbly flow occasionally with large bubbles at the middle position. In other cases, e.g. $U_{s l}=1.5 \mathrm{~m} / \mathrm{s}$ and $U_{s g}=1.05 \mathrm{~m} / \mathrm{s}$ (Figure 11 (f)), the flow regime remains the same, however due to the reduced void fraction the gas phase is significantly accelerated as it flows towards the bottom.

The cross-sectional void fraction distributions at different positions also demonstrate the effect of the upstream top bend on the flow development in the downward section. Figure 12 shows the phase distributions, respectively at the top, middle and bottom positions of the downward section for three different superficial air velocities and a fixed superficial water velocity of $1.0 \mathrm{~m} / \mathrm{s}$. In the figure, the distributions of the void fraction along two perpendicular chords are given in (a), and a contour plot of the void fraction distribution is given in (b). It can be seen from these plots that, for all superficial air velocities, the void fraction on the $90^{\circ}$ side quarter of the pipe cross-section is much less than that of its opposite quarter, i.e. the $270^{\circ}$ side quarter. Meanwhile the void fraction is distributed fairly evenly 
along $0^{\circ}-180^{\circ}$ direction. As mentioned above the $90^{\circ}$ position corresponds to the outside curvature of the upstream bend, and $270^{\circ}$ to the inside of the upstream bend, thus the asymmetry of the void fraction distribution over the cross-section area of the pipe should be due to the centrifugal effect of the upstream bend. From the plots of the middle and bottom positions, it also can be seen that, the void fraction distribution becomes quite symmetric over the cross-section areas.

\subsection{Liquid film development and its circumferential distribution}

As the liquid film only exists in annular flow, this part of the results are mainly based on the data from the flow conditions in which annular regime can be established.

\subsubsection{Average liquid film thickness development}

Figure 13 (a), (b) and (c) show the average liquid film thickness against the superficial air velocity at three different fixed superficial water velocities in downward flows. The average film thickness at each axial position is obtained from the 4 film thicknesses at different circumferential positions at that axial position.

From the plots it can be seen that the average liquid film thickness development in the downward flows is dependent on not only the superficial air velocity, but also the superficial water velocity. For $U s l=0.1 \mathrm{~m} / \mathrm{s}$ (Figure 13 (a)), the average liquid film thicknesses at the middle and bottom positions are similar to each other over the whole range of the air flow rates tested. The liquid film at the top position is significantly thinner than those at the lower positions when the air velocity is low. However, once the $U_{s g}$ is higher than $15 \mathrm{~m} / \mathrm{s}$ the film thickness at the top position approaches those at the lower positions.

In the case of $U s l=0.3 \mathrm{~m} / \mathrm{s}$ (Figure 13 (b)), the average liquid film thicknesses at the middle and bottom positions are also close to each other over the whole range of the air flow rates 
tested. The film at the top position is notably thinner than those in the lower positions for whole range of superficial air velocity.

In the case of $U s l=1.0 \mathrm{~m} / \mathrm{s}$ (Figure 13 (c)) it can be noted that the film thickness at the top position against the superficial gas velocity decreases more steeply than those at the lower positions, which indicates that, the film thickness varied faster in the upper part than in the lower part of the section. When the $U_{s g}$ is higher than $14 \mathrm{~m} / \mathrm{s}$, the film thicknesses at the middle and bottom positions converged together, while the film thickness at the top position becomes thinner and diverged towards lower values than those at lower positions.

The liquid film thickness ratios versus the axial distances (i.e. 5D, 30D and 46D after the top bend) at different flow conditions are also presented to demonstrate the downward liquid film development (Figure 14). Similar to the method used for void fraction ratio, the film thickness ratio at any particular axial position is defined as the ratio of the film thickness at this position to that at the position of $46 \mathrm{D}$ from the bend. Hence, the film thickness ratio for any velocity at the position of $46 \mathrm{D}$ is unity. In all plots of the Figure 14 , it can be noted that the film thickness ratio at the position of 5D shows significant variations under different flow conditions. More specifically, at low liquid flow rates, e.g. $U_{s l}=0.1 \mathrm{~m} / \mathrm{s}$ (Figure 14 (a)), the liquid film thickness ratio at the top position is much less than that at lower positions when the air flow rate is relatively low, while it is fairly close to 1.0 when the air flow rate is over $12 \mathrm{~m} / \mathrm{s}$; at high liquid flow rates, e.g. $U_{s l}=1.0 \mathrm{~m} / \mathrm{s}$ (Figure 14 (f)), the liquid film thickness ratio at the top position is close to that at the middle position when the air flow rate is about $5.3 \mathrm{~m} / \mathrm{s}$, while it becomes much less than that at the middle position when the air flow rate is increased over $10.0 \mathrm{~m} / \mathrm{s}$. However, the film thickness ratio at the position of 30D is close to or slightly larger than unity, regardless of the flow conditions. It can be inferred that the liquid film ratio at the position of $5 \mathrm{D}$ from the upstream bend is more sensitive to flow conditions, this could be because of the bend effect. In contrast the bend effect on film 
thickness becomes considerably lower as the flow reached the 30D or is further away from the upstream bend.

\subsubsection{Circumferential distribution of the liquid film}

Figure 15 illustrates the circumferential distributions of liquid film for downward flows at $U_{s l}=0.1 \mathrm{~m} / \mathrm{s}$, with $U_{s g}=3.0$ and $28.8 \mathrm{~m} / \mathrm{s}$ (Figure 15 (a) and (b), respectively). It is noted that in the former case, with low air flow rate the film profile at the middle position is almost identical to that at the bottom position, but is quite different from that at the top position, where the thickest film appears at the $90^{\circ}$ position (corresponding to the outside of the upstream top bend) and the thinnest film at $270^{\circ}$ position (corresponding to the inside of the upstream top bend), in comparing with those at other circumferential positions.

This is due to the effect of centrifugal force of the upstream top bend on the liquid distribution. In the latter case, with a high air flow rate, an asymmetric film profile is observed at the top, middle and bottom positions, suggesting that the centrifugal force effect on the liquid film distribution persisting through the whole downward section. It is worth noting that the circumferential film thickness profiles are fairly symmetric about the $90^{\circ}-270^{\circ}$ axis. This feature is observed for almost all the flow conditions tested in this study.

Figure 16 illustrates the circumferential distributions of liquid film at the downward flows for $U_{s l}=0.3 \mathrm{~m} / \mathrm{s}$, with three different superficial air velocities. In all cases the effect of centrifugal force of the upstream top bend on the film circumferential profile is observed at the top position. Also for all three cases the profile related to the middle position is almost identical to that at the bottom position. The centrifugal force effect of the upstream bend on these lower positions is insignificant. It is also observed that the average liquid film thickness at the top position is significantly less than those at lower axial positions.

Figure 17 illustrates the circumferential distributions of liquid film for $U_{s l}=1.0 \mathrm{~m} / \mathrm{s}$ and for $U_{s g}=9.80$ and $18.50 \mathrm{~m} / \mathrm{s}$. The circumferential profile of the film thickness at the top position 
shows an extremely high liquid film appearing on the $90^{\circ}$ side, while at $180^{\circ}, 270^{\circ}$ and $0^{\circ}$ sides the film thickness is fairly even. Again the film profiles at the middle and bottom positions are similar to each other.

\subsection{The effect of pipe diameter on liquid film thickness}

In order to examine the pipe diameter's effect on liquid film thickness in downward annular flows, the film thickness data from the publicised studies on downwards annular flows in pipes of different diameters have been gathered. Film thickness data from this study and those publicised studies are compared with the predicted film thickness using the correlation developed by Henstock and Hanratty (1976). The correlation is based on both liquid film and gas Reynolds Numbers as follows:

$$
\frac{t}{D}=6.59 F /(1+1400 F)^{1 / 2}
$$

Where $t$ is film thickness, $D$ the internal diameter of the pipe, and parameter $F$ is defined as

$$
F=K\left(v_{L} / \nu_{G}\right)\left(\rho_{L} / \rho_{G}\right)^{1 / 2} R e_{g}^{-0.9}
$$

and further the parameter $K$ is defined as:

$$
K=\left[\left(0.707 R e_{l}^{0.5}\right)^{2.5}+\left(0.0379 R e_{l}^{0.9}\right)^{2.5}\right]^{0.4}
$$

where $v_{L}$ and $v_{G}$ are the kinematic viscosity of the liquid and gas, respectively. The Reynolds numbers $\operatorname{Re}_{g}$ and $\operatorname{Re}_{l}$ are based on the gas flow and liquid flow rates, respectively. Assuming in downward annular flow the entrained liquid rate is insignificant $\mathrm{Re}_{l}$ can also be replaced by the liquid film Reynolds number $\operatorname{Re}_{l f}$.

The experimental data sets used for the comparisons are from downward annular flows in different diameter pipes, i.e., 31.8mm, 38.2mm (Webb and Hewitt, 1975), 50.8mm (Chien 
\&Ibele 1964) and $101.6 \mathrm{~mm}$ (this study). The experimental conditions for these data sets are listed in Table 2.

Figure 18 shows a plot with the predicted film thickness using Equations (3-5), against the measured film thickness in terms of thickness to pipe diameter ratio $t / D$. It appears that in general the correlation overestimates the film thickness for all data sets used. However, it agrees reasonably well with small diameter pipe results. The degree of overestimation increases as the diameter increases. This might be interpreted using the Eotvos number $\mathrm{Eo}=\Delta \rho g D^{2} / \sigma$, where $\Delta \rho$ is the density difference between water and air, $\sigma$ is the surface tension of water. When the pipe diameter is increased, the surface tension's effect on the gas, liquid flow is getting weaker in comparison with that of the gravitational force, which can lead to fundamental changes to the flow. Kataoka and Ishii (1987) suggested the criteria for such changes is that Eo>100. For example in vertical annular flows in a $31.8 \mathrm{~mm}$ i.d. pipe it was found that disturbance waves can achieve their circumferential coherence (Zhao et al 2013); while in much large pipes only incoherent disturbance waves were found on the liquid film. This change could lead to further two changes which may affect the applicability of Eqation (3-5) for large diameter pipes. First is that the velocity profile of liquid film, hence the film average velocity become different from that in small diameter pipes; Second is the liquid entrainment rate changes due to the change of interfacial wave structure.

In comparing the measured mean film thicknesses (obtained at $46 \mathrm{D}$ axial position downstream of bend 1 with existing models, reference is also made to earlier theoretical studies on falling films based on Nusselt's (1916) falling film theory:

$$
t=\left[\frac{3 v_{L}{ }^{2} R e_{l f}}{4 g}\right]^{1 / 3}
$$

where $R e_{l f}$ the liquid film Reynolds number based on the liquid film mass flux $\dot{m}_{l}$. Nusselt arrived at the equation by taking a force balance on an elemental liquid film assuming 
viscous flow and that no shear or waves occur on the liquid surface. Kapitza's (1965) modification to account for these waves and surface tension resulted in the following relation:

$$
t=\left[\frac{2.4 v_{L}^{2} R e_{l f}}{4 g}\right]^{1 / 3}
$$

A large number of empirical and semi-empirical correlations have been proposed with the form of Nusselt's theory such that:

$$
t=A\left(v_{L}^{2} / g\right)^{1 / 3} R e_{l f}^{n}
$$

Where $A$ and $n$ are regression constants. The models of Ganchev (1972), Kosky (1971), Mudawar \& El-Masri (1995) have very similar slopes and predictions due to the close values of their respective $A, n$; they are in agreement with our data up to $R e_{l f}=8000$ but dramatically lose accuracy beyond that even though their range of application are between $R e_{l f}$ ranges of 1000 and 10000 . Fiend (1960) model agrees with the large pipe data up to $R e_{l f}=10000$ while Brauner (1987) predicts well within the range $R e_{l f}=10000-14500$. In fact, only the model of Karapantsios \& Karabelas (1995) caters for $R e_{l f}>10000$ up to 11080 only, while our measured film thicknesses were obtained at Reynolds number ranges of 4000-20200. At high film Reynolds numbers the large deviations produced may be as a result of higher interfacial friction. As Figure 19 (b) shows values of $A=1.4459$ and $n=$ 0.3051 fit the large pipe data best. This indicates an increase in intercept and a decrease in slope when compared to the existing relations derived from smaller pipes and is clearly visible in Figure 19 (a). shows the value of $A$ and $n$ previously obtained experimentally by several investigators. It should be noted that differing values of $A$ and $n$ by the various studies over the years only serve to slightly change the slope or magnitude of the respective dimensionless film thickness curves within the same $R e_{l f}$ range. 
This fact is shown in Figure 19 (a) where the current data is plotted together with the models in Table 3. It can be seen that only a handful of the predictions (Nusselt, Kapiza, and Brauner) are within the vicinity of our large pipe experimental film thicknesses. The models of Ganchev (1972), Kosky (1971), Mudawar \& El-Masri (1995) have very similar slopes and predictions due to the close values of their respective $A, n$; they are in agreement with our data up to $R e_{l f}=8000$ but dramatically lose accuracy beyond that even though their range of application are between $R e_{l f}$ ranges of 1000 and 10000. Fiend (1960) model agrees with the large pipe data up to $R e_{l f}=10000$ while Brauner (1987) predicts well within the range $R e_{l f}$ $=10000-14500$. In fact, only the model of Karapantsios \& Karabelas (1995) caters for $R e_{l f}>$ 10000 up to 11080 only, while our measured film thicknesses were obtained at Reynolds number ranges of 4000-20200. At high film Reynolds numbers the large deviations produced may be as a result of higher interfacial friction. As Figure 19 (b) shows values of $A=1.4459$ and $n=0.3051$ fit the large pipe data best. This indicates an increase in intercept and a decrease in slope when compared to the existing relations derived from smaller pipes and is clearly visible in Figure 19 (a).

\section{Conclusions}

In this study, WMS and film thickness probes are used to investigate the effects of $180^{\circ}$ bends on behaviours of gas/liquid flows in a downward section of a vertical serpentine large diameter pipeline, covering the superficial air and water velocities ranged from 0.15 to 30.0 $\mathrm{m} / \mathrm{s}$ and from 0.07 to $1.5 \mathrm{~m} / \mathrm{s}$, respectively. The following conclusions can be drawn from the experimental investigation that was carried out in this study:

1. The cross-sectional phase distributions measured at the top position show a significantly higher void fraction on the half corresponding to the inside of upstream top bend than that on 
the half outside of the bend. This asymmetry is reduced as the flow moves towards the lower axial positions. However, it is also noted that in contrast, the cross-sectional phase distributions are remarkably symmetrical with respect to the $90^{\circ}-270^{\circ}$ axis. For most flow conditions tested, the cross-section void fraction distribution at the middle and bottom positions are close to each other, which may suggest that the flow has been fairly well developed in the downward section after 30D from the upstream top bend.

2. In most downward annular flows tested, the average liquid film at the top axial position is significantly different from those at the lower axial positions. However, the liquid film thicknesses at middle and bottom positions are remarkably close to each other, which may again suggest that, the flow is reasonably developed in the downward section at and after 30D from the upstream top bend. However, when in a combination of low liquid loading and high air velocity the liquid film circumferential profile is still uneven at an axial position of 46 pipe diameters from the top bend, suggesting that the bend effect persists through the whole downward section hence fully developed flow cannot strictly be said to have been achieved.

3. The mean film thickness data from this study was compared to existing correlations and theoretical models. It was observed that clearly the current data presented a distinctly different slope to those of the correlations suggesting a change in the film structure for large diameter pipes.

\section{Acknowledgement}

A. Almabrok would like to express sincere appreciation to the Libyan Government for providing the funding of his doctoral studies while A. Aliyu acknowledges Nigeria's Petroleum Technology Development Fund for the scholarship granted for his doctorate 
studies. The authors would gratefully acknowledge the courtesy data processing and image reconstruction software, and technical support to this study, by Prof Hampel and his group at Helmholtz-Zentrum Dresden-Rossendorf, Germany, and by Prof Da Silva and his group at Universidade Tecnológica Federal do Paraná, Brazil.

\section{Appendix}

Table A-1 Flow conditions used throughout this study

Table A-2 Summary of instruments installed on the Serpent rig 


\section{References}

Abdulkadir, M., D. Zhao, Azzi, A., Lowndes, I. S. \& Azzopardi, B. J., (2012).Two-phase airwater flow through a large diameter vertical $180^{\circ}$ return bend.Chemical Engineering Science, $79,138-152$

Alves, G.E., (1954). Co-current liquid-gas flow in a pipeline contractor. Chemical Engineering Progress, 50, 449-456.

Anderson, G.H. \& Hills, P.D., (1974). Two-phase annular flow in tube bends. Symposium on Multiphase flow Systems. University of Strathclyde, Glasgow, paper J1, Published as Institution of Chemical Engineers Symposium, series no. 38.

Barnea, D, Shoham, O. \& Taitel, Y. (1982). Flow pattern transition for downward inclined two-phase flow: Horizontal to vertical. Chemical Engineering Science, 37, 735-740.

Brauer, H., 1956. Flow and heat transfer at falling liquid films, VDI Forschungsh.

Brauner, N., 1987. Roll wave celerity and average film thickness in turbulent wavy film flow. Chemical Engineering Science, 42(2), pp.265-273.

Brotz, W., 1954. Uber die Vorausberedinung der Absorptions geschwineig von Gayen instromenden flussig kectsschichten. Chem Ing. Tech., 26, pp.470-8.

Brown, D. J., Jensen, A., \& Whalley, P. B., (1975). Non-equilibrium effects in heated and unheated annular two-phase flow. ASME, paper no. 75-WA/HT-7.

Chien, Sze-Foo, and Ibele, W., (1964). Pressure Drop and Liquid Film Thickness of TwoPhase Annular and Annular-Mist Flows. ASME Journal of Heat Transfer, 86, 89-96

Chong, L. Y., Azzopardi, B. J., \& Bate, D. J., (2005). Calculation of conditions at which dryout occurs in the serpentine channels of fired reboilers. Chemical Engineering Research and Design, 83, 412-422.

Da Silva, M. J., Schleicher, E. \& Hampel, U., (2007). Capacitance wire-mesh sensor for fast measurement of phase fraction distributions. Measurement Science and Technology, 18, $2245-2251$.

Da Silva, M.J., Thiele, S., Abdulkareem, L., Azzopardi, B.J. \& Hampel, U., (2010). Highresolution gas-oil two-phase flow visualization with a capacitance wire-mesh sensor. Flow Measurement and Instrumentation, 21, 191-197.

Fiend, K., 1960. Stromungsuntersuchungen bei gegenstrom von Riesel-Filmen und Gas in lotrechten Rohren, VDl-Forsclurngsh. 
Ganchev, B.G., Kozlov, V.M. \& Orlov, V. V, 1972. Some results of falling liquid film studies by stroboscopic visualization technique. Zh. Prik. Mekh. Tekh., 2(140).

Gill, L.E., Hewitt, G.F., Hitchon, J.W., \& Lacey, P.M.C, (1963). Sampling probe studies of the gas core in annular two phase flow-1: The effect of length on phase and velocity distribution. Chemical Engineering Science, 18, 525-535.

Gill L. E. \& Hewitt G. F., (1966). Sampling probe studies of the gas core in annular two phase flow: III, Distribution of velocity and droplet flow rate after injection through axial jet. AEREM 1202.

Golan, L.P. \& Stenning, A.H. (1969). Two-Phase Vertical Flow Maps, Proc. Inst. Mech. Eng. 184(3C), 110-116.

Hawkes, N. J., Lawrence, C. J. \& Hewitt, G. F., (2000). Studies of wispy-annular flow using transient pressure gradient and optical measurements. International Journal of Multiphase Flow, 26, 1565-1582.

Hazuku, T., Takamasa, T. \& Matsumoto, Y., (2008). Experimental study on axial development of liquid film in vertical upward annular two-phase flow. International Journal of Multiphase Flow, 34, 111-127.

Henstock, W. H., \& Hanratty, T. J., (1976). The interfacial drag and the height of the wall layer in annular flows. AIChE J. 22, 990-1000.

Hewitt, G.F. and Hall-Taylor, N.S., (1970). Annular Two-Phase Flow, Pergamon, Oxford, UK.

Hills, P.D., (1973). A Study of Two-Phase (Gas-Liquid) Flow in a Tube Bend. PhD Thesis, Imperial College, London.

Hoang, K., Davis, M.R., (1984). Flow structure and pressure loss for two-phase flow in round bends. J. Fluids Eng, 106, 30-37.

James, P. W., Azzopardi, B. W., Graham, D. I., \& Sudlow, C.A., (2000). The effect of a bend on droplet distribution in two-phase flow. International Conference on Multiphase Flow in Industrial Plants, Bologna, 13-15 September.

Kapitza, P.L., 1965. Collected papers of Kapitza 1938-1964. In D. Ter-Harr, ed. New York: Pergamon Press, pp. 662-709.

Karapantsios, T.D. \& Karabelas, A.J., 1995. Longitudinal characteristics of wavy falling films. International Journal of Multiphase Flow, 21(I), pp.119-127.

Kelessidis, V.C. \& Dukler, A. (1989). Modeling flow pattern transitions for upward gasliquid flow in vertical concentric and eccentric annulis. International Journal Multiphase Flow. 15, 173-191. 
Kataoka, I.\& Ishii, M., (1987). Drift-flux model for large diameter pipe and new correlation for pool void fraction. International Journal of Heat Mass Transfer 30, 1927-1939.

Kosky, P.G., 1971. Thin liquid films under simultaneous shear and gravity forces. International Journal of Heat and Mass Transfer, 14(8), pp.1220-1224. Available at: http://www.sciencedirect.com/science/article/pii/001793107190216X.

Lao, L., Antonio, L., Lawrence, C. \& Hewitt, G., (2004). Experimental studies of the effects of inlet geometry on the annular flow development at high mass fluxes, 5th International Conference on Multiphase Flow, ICMF'04, paper no. 22, Yokohama, Japan.

Mudawar, I. \& El-Masri, 1988. Boiling Incipience in Plane Rotating Water Films. Transactions of the ASME, 110(May), pp.126-129.

Nusselt, W., 1916. Die oberflachen Kondensation das Wasserdampfes. VDI-Zeitschrift, 54, pp.1154-1178.

Omebere-Iyari, N. K., Azzopardi, B. J., Lucas, D., Beyer, M. \& Prasser, H. M., (2008). Gas/liquid flow in large risers. International Journal of Multiphase Flow, 34, 461-476.

Oshinowo, T. \& Charles, M.E., (1974). Vertical two-phase flow-Part 1: Flow pattern correlations. The Canadian Journal of Chemical Engineering, 52, 25-35.

Pickering, P. F., Hewitt, G. F., Watson, M. J., Hale, C. P., (2001).The prediction of flows in production risers - truth \& myth, IIR Conference on the Latest Developments in Riser Designfor Deep \& Ultra Deep Water, Aberdeen, 1-16.

Poulson, B., 1991. Measuring and modelling mass transfer at bends in annular flow two phase flow. Chemical Engineering Science, 46, 1069-1082.

Prasser, H.-M., Beyer, M., Carl, H., Gregor, S., Lucas, D., Pietruske, H., Schütz, P. \& Weiss, F.-P, (2007). Evolution of the structure of a gas-liquid two-phase flow in a large vertical pipe. Nuclear Engineering and Design, 237, 1848-1861.

Schlegel, J. P., S. Miwa, S. Chen, T. Hibiki, M. Ishii, (2012). Experimental study of twophase flow structure in large diameter pipes, Experimental Thermal and Fluid Science, ISSN 0894-1777, http://dx.doi.org/10.1016/j.expthermflusci.2012.01.034. (http://www.sciencedirect.com/science/article/pii/S0894177712000465), 41, 12-22.

Smith, T. R., J.P. Schlegel, T. Hibiki, M. Ishii, (2012).Two-phase flow structure in large diameter pipes, International Journal of Heat and Fluid Flow, ISSN 0142-727X, http://dx.doi.org/10.1016/j.ijheatfluidflow.2011.10.008.

(http://www.sciencedirect.com/science/article/pii/S0142727X11001469), 33(1), 156-167.

Takahama, H. \& Kato, S., 1980. Longitudinal flow characteristics of vertically falling liquid films without concurrent gas flow. , 6, pp.203-215.

Usui, K., Aoki, S., \& Inoue, A., (1980). Flow behaviour and pressure drop of two-phase flow through C-shaped bend in a vertical plane (I): Upward Flow. Journal of Nuclear Science and Technology, 17, 875-887. 
Usui, K., Aoki, S., \& Inoue, A., (1981). Flow behaviour and pressure drop of two-phase flow through C-shaped bend in a vertical plane (II): Downward Flow. Journal of Nuclear Science and Technology, 18, 179-190.

Usui, K., Aoki, S., \& Inoue, A. (1983). Flow behaviour and phase distributions in two phase flow around inverted U-bend. Journal of Nuclear Science and Technology, 20, 915-928.

K. Usui, (1989). Vertically downward two-phase flow: II. Flow regime transition criteria, J. Nucl. Sci. Technol. 26 1013-1022. DOI: http://dx.doi.org/10.1080/18811248.1989.9734422

Wang, C. C., Chen, I. Y., Yang, Y. W. \& Chang, Y. J., (2003). Two-phase flow pattern in small diameter tubes with the presence of horizontal return bend. International Journal of Heat and Mass Transfer, 46, 2976-2981

Wang, C. C., Chen, I. Y., Yang, Y. W. \& Hu, R., (2004). Influence of horizontal return bend on the two-phase flow pattern in small diameter tubes. Experimental Thermal and Fluid Science, 28, 145-152.

Wang, C. C., Chen, I. Y., Lin, Y. T. \& Chang, Y. J., (2008). A visual observation of the airwater two-phase flow in small diameter tubes subject to the influence of vertical return bends. Chemical Engineering Research and Design, 86, 1223-1235.

Webb D.R. \& Hewitt G.F., (1975). Downward co-current annular flow, International Journal of Multiphase Flow, 2, 35-49

Wolf, A., Jayanti, S. \& Hewitt, G.F., (2001). Flow development in vertical annular flow. Chemical Engineering Science, 56, 3221-3235.

Zhao,Y., Markides, C.N., Matar, O.K., Hewitt, G.F., (2013), Disturbance Wave Development in Two-Phase Gas-Liquid Upwards Vertical Annular Flow. International Journal of Multiphase Flow, 55, 111-129. 


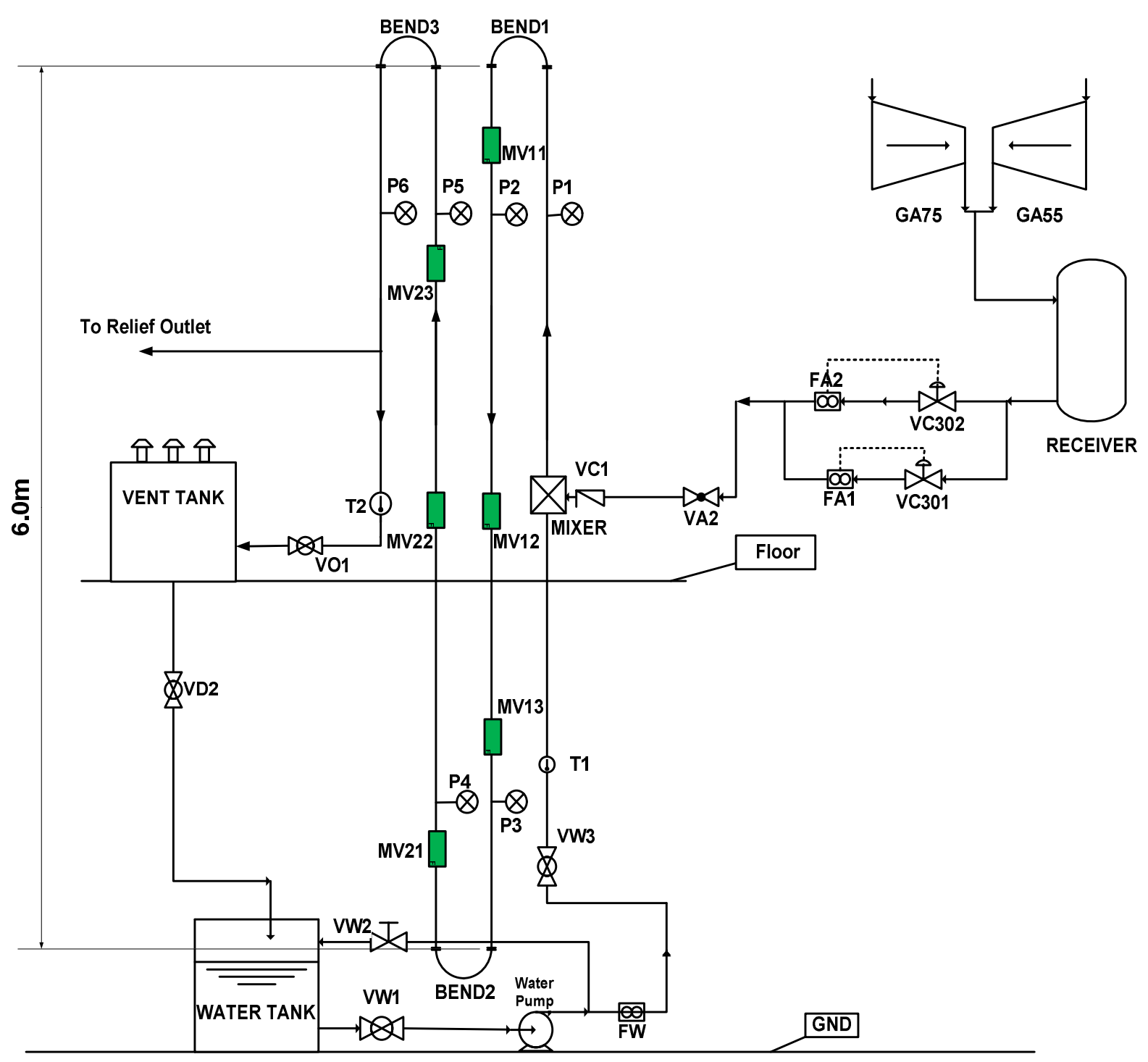

Figure 1: Schematic of the Serpent rig 


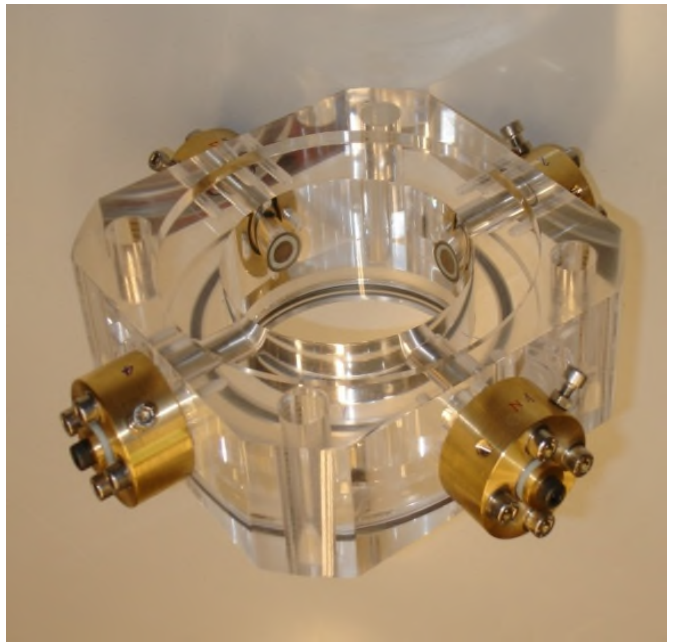

(a)

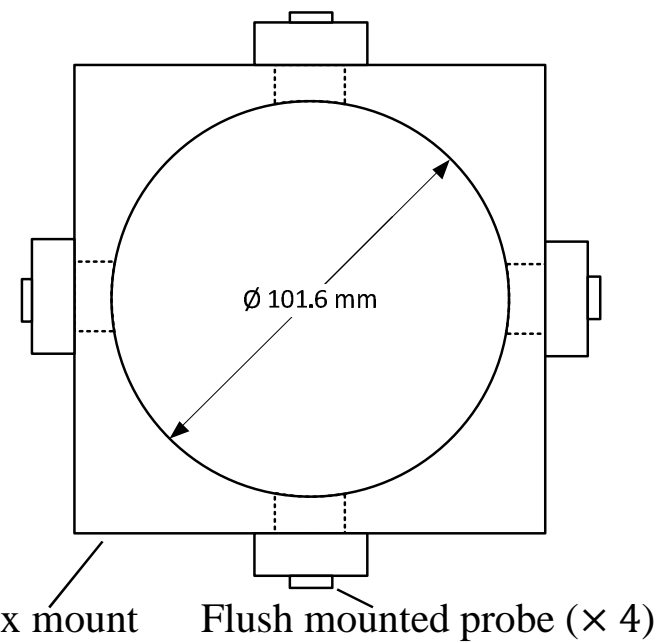

(b)

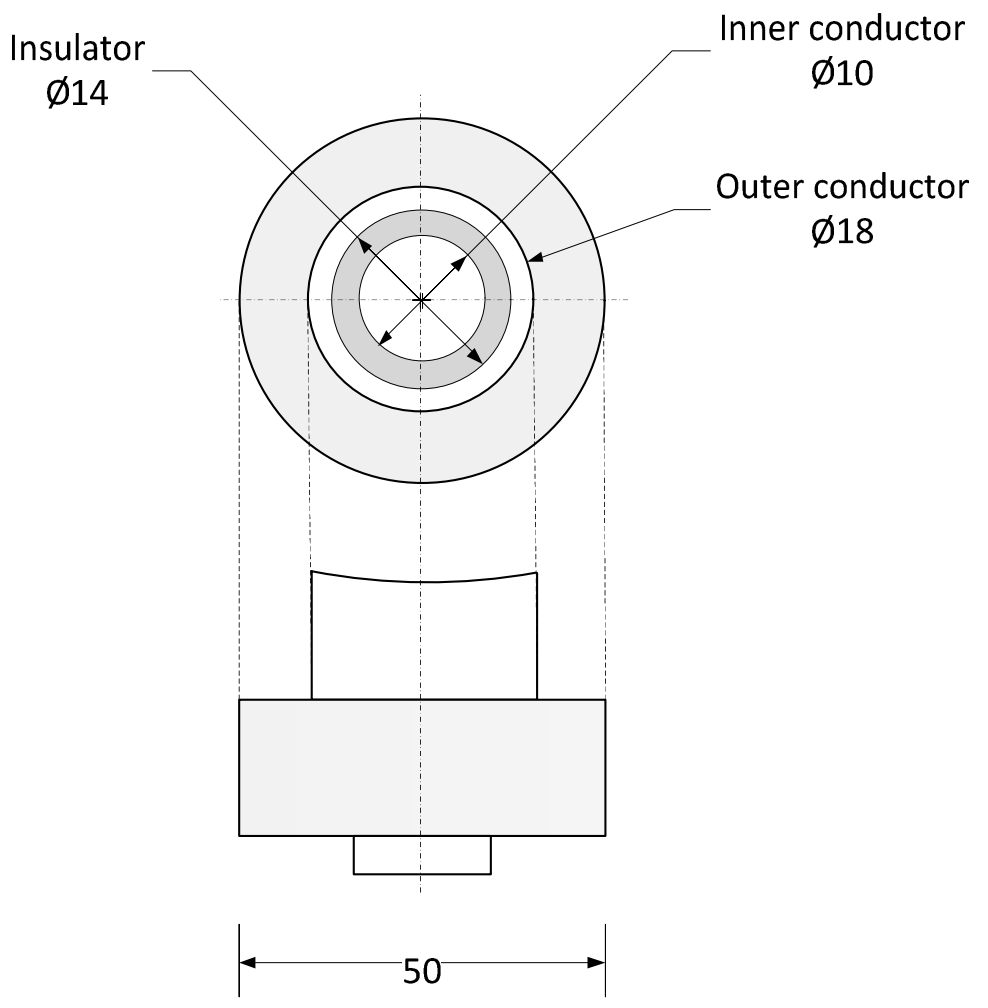

(c)

Figure 2: Conductivity liquid film thickness sensor (a) Photograph showing sensor spool with four flush mounted probes (b) Schematic of sensor spool (c) Details of individual probe design (All dimensions in $\mathrm{mm}$ ) 


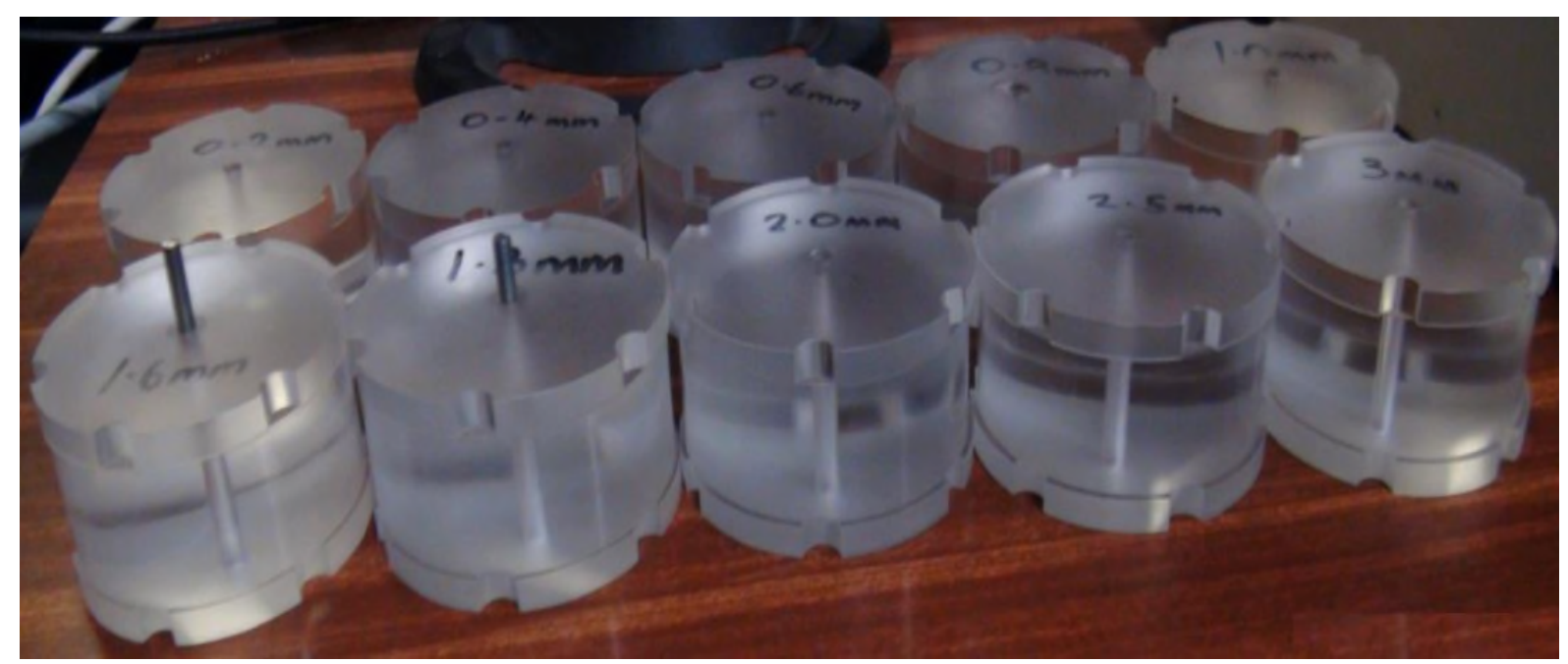

(a)

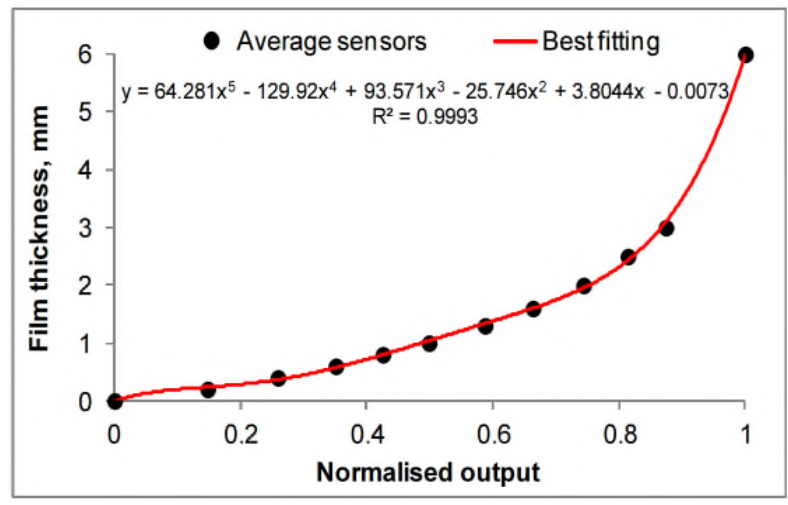

(b)

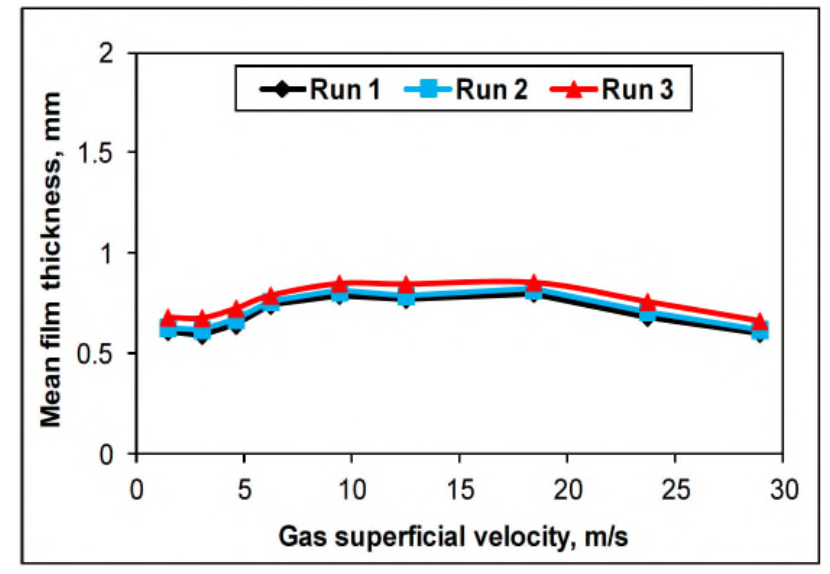

(c)

Figure 3: (a) Blocks of different diameters used for probe calibration (b) A sample film thickness calibration curve (used for top position downward section) (c) Repeatablity of liquid film measurements 


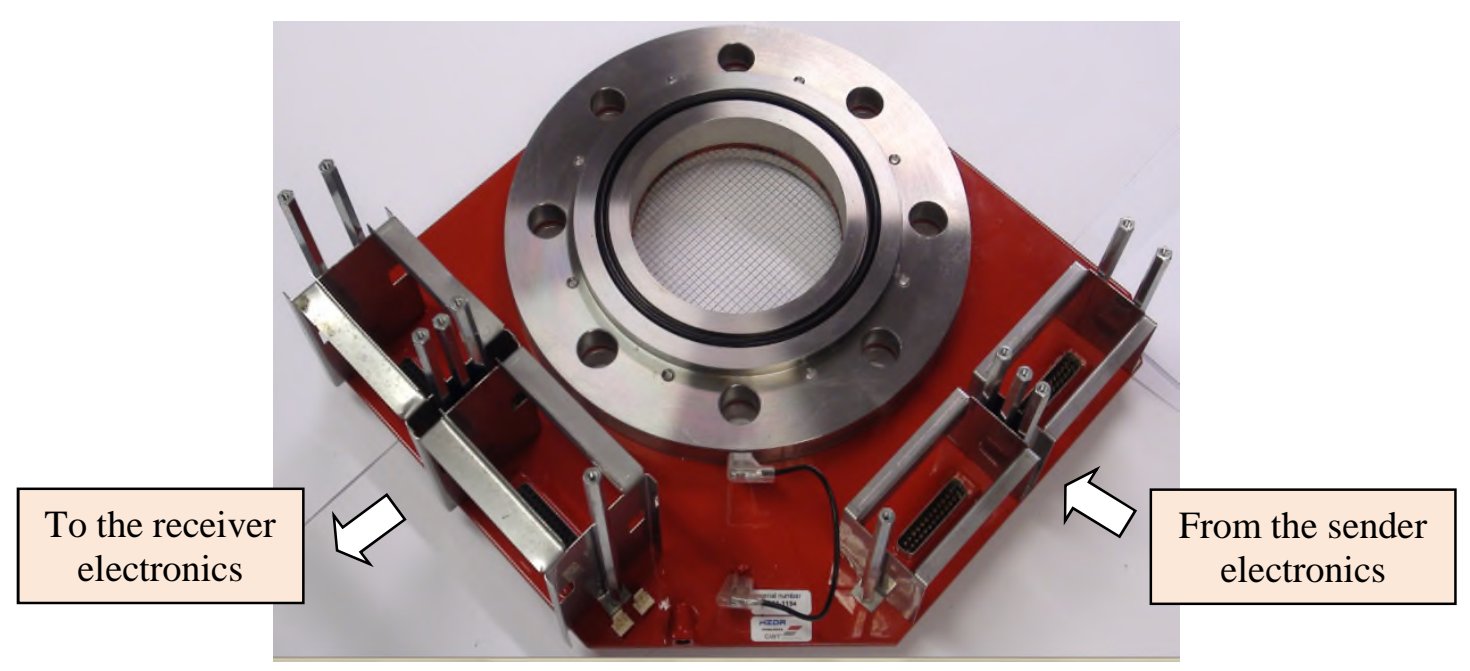

(a)

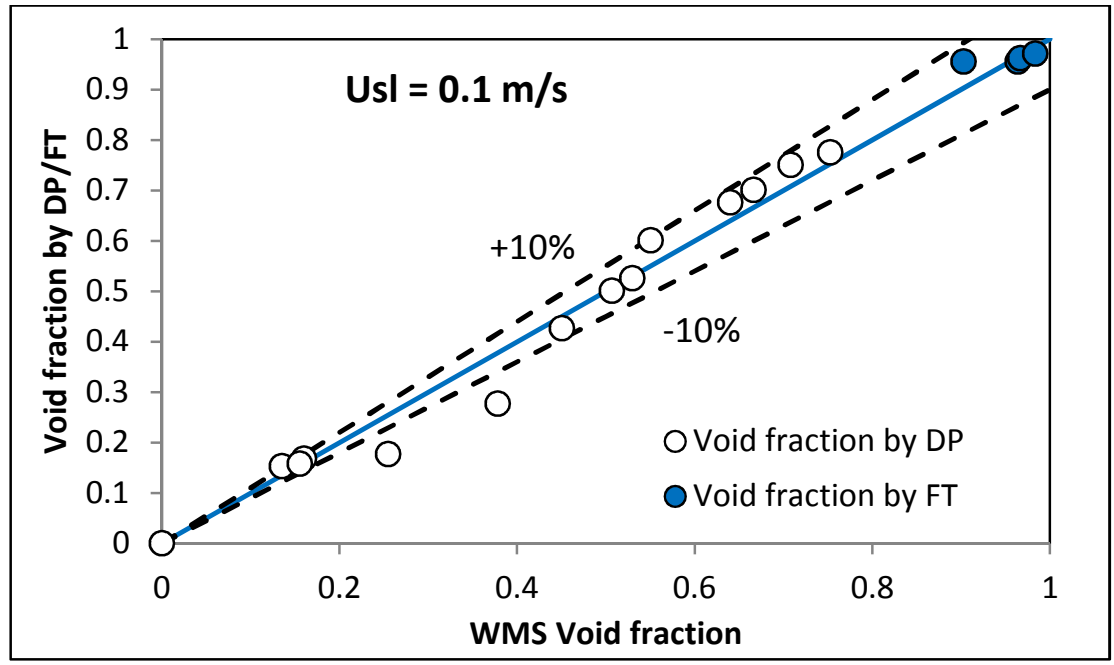

(b)

Figure 4: (a) 32×32 WMS spool used in this study and (b) Comparison of measured void fractions using WMS and other methods 


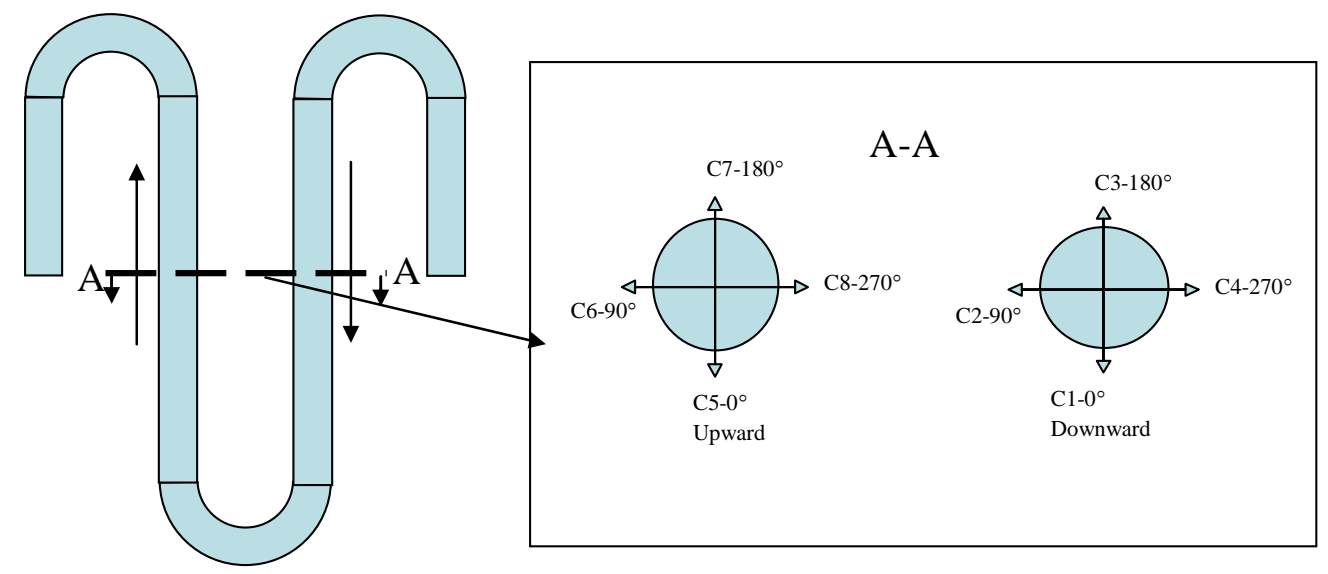

(a)

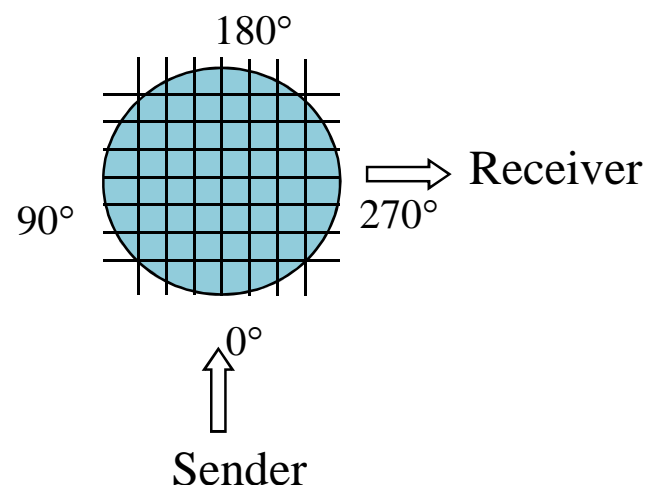

(b)

Figure 5: Circumferential positions of the film sensors (a) and cross-section of WMS (b) 


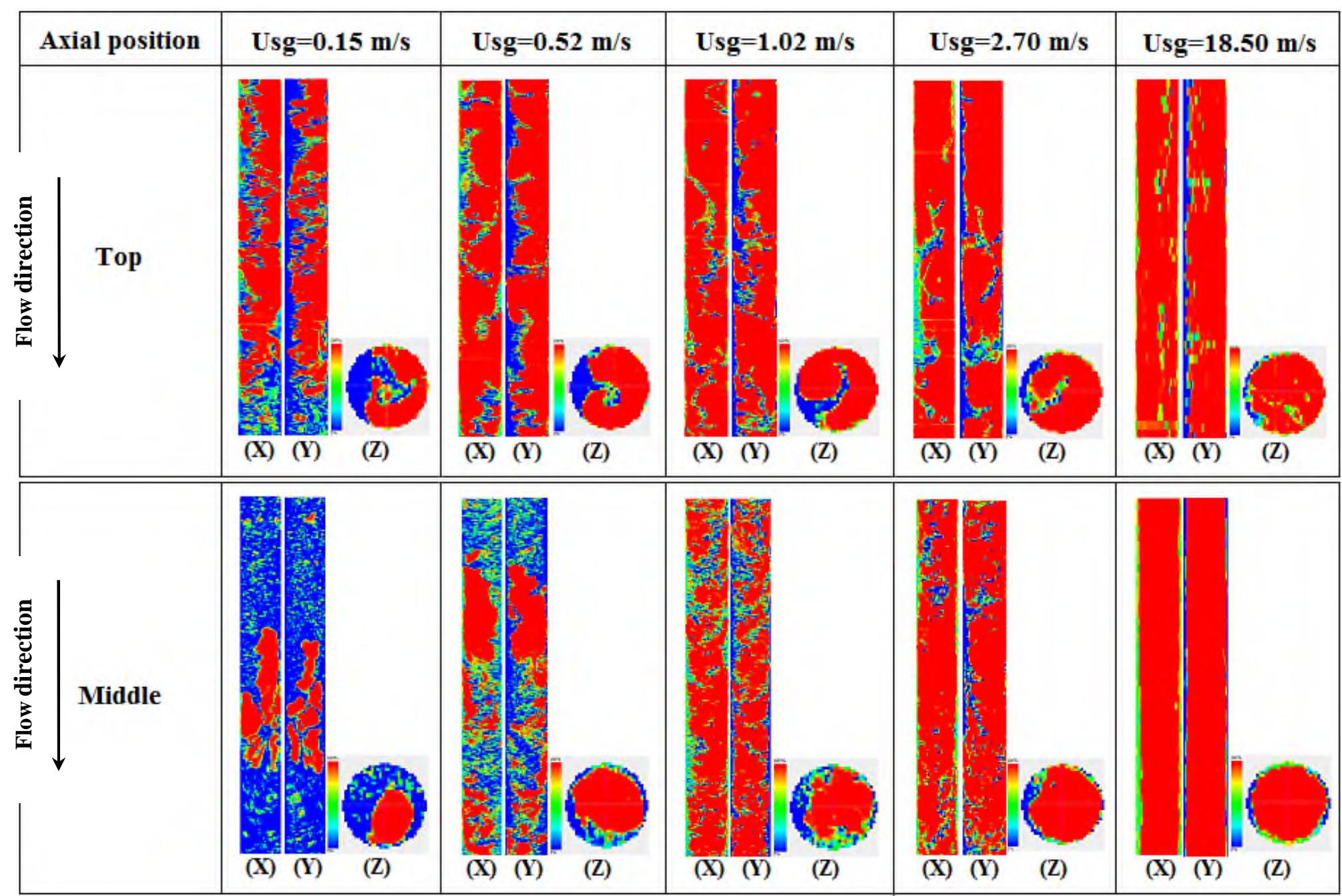




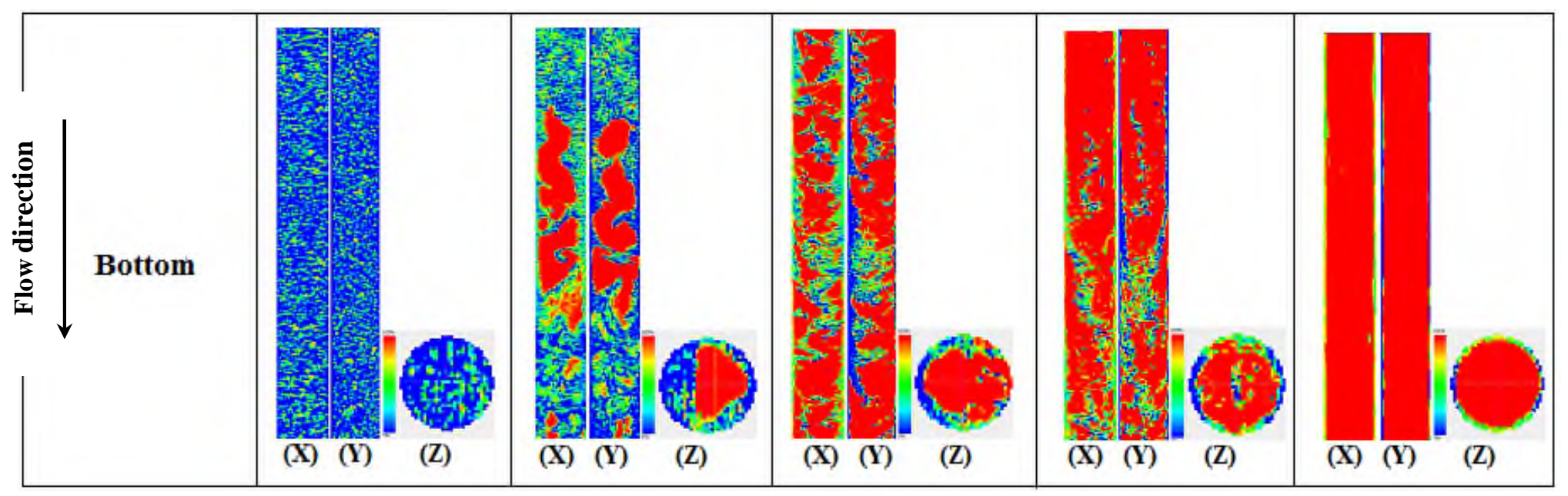

Figure 6: Axial slice images (X and $\mathrm{Y}$ ) and cross-section images $(\mathrm{Z})$ phase distribution at different axial positions and different flow conditions in the downward section. In each panel image $\mathrm{X}$ is obtained by axially slicing along $0^{\circ}-180^{\circ}$ direction and image $\mathrm{Y}$ along $90^{\circ}-270^{\circ}$ direction, both representing a $1000 \mathrm{~mm}$ long pipe section. The superficial air velocities $\left(U_{s g}\right)$ are shown in the figure. The superficial water velocity $\left(U_{s l}\right)$ is kept at $1.0 \mathrm{~m} / \mathrm{s}$. In the images, the colour varies from blue to red representing the void fraction changing from 0 (i.e. water) to $100 \%$ (i.e. air). 


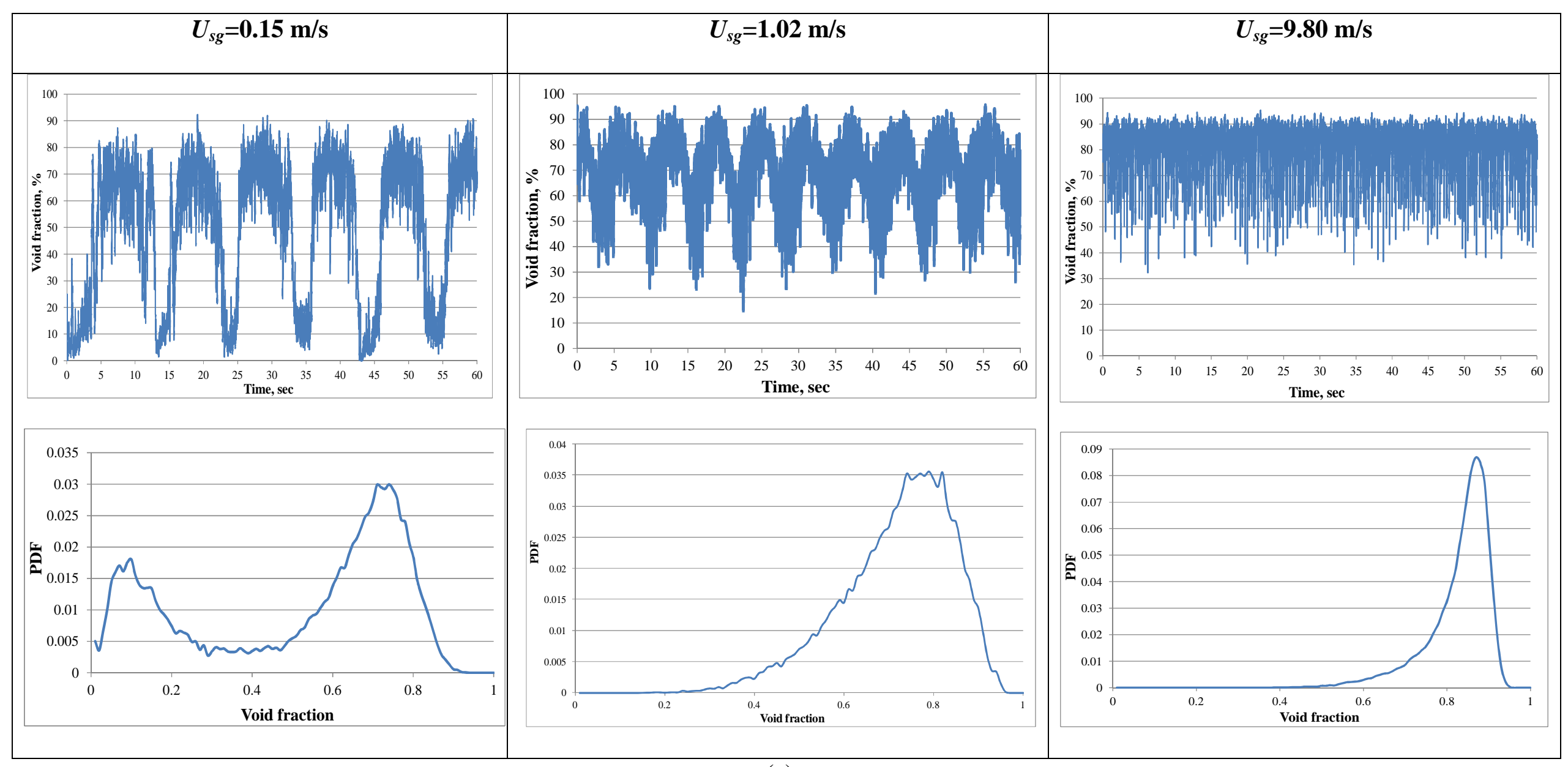

(a) 


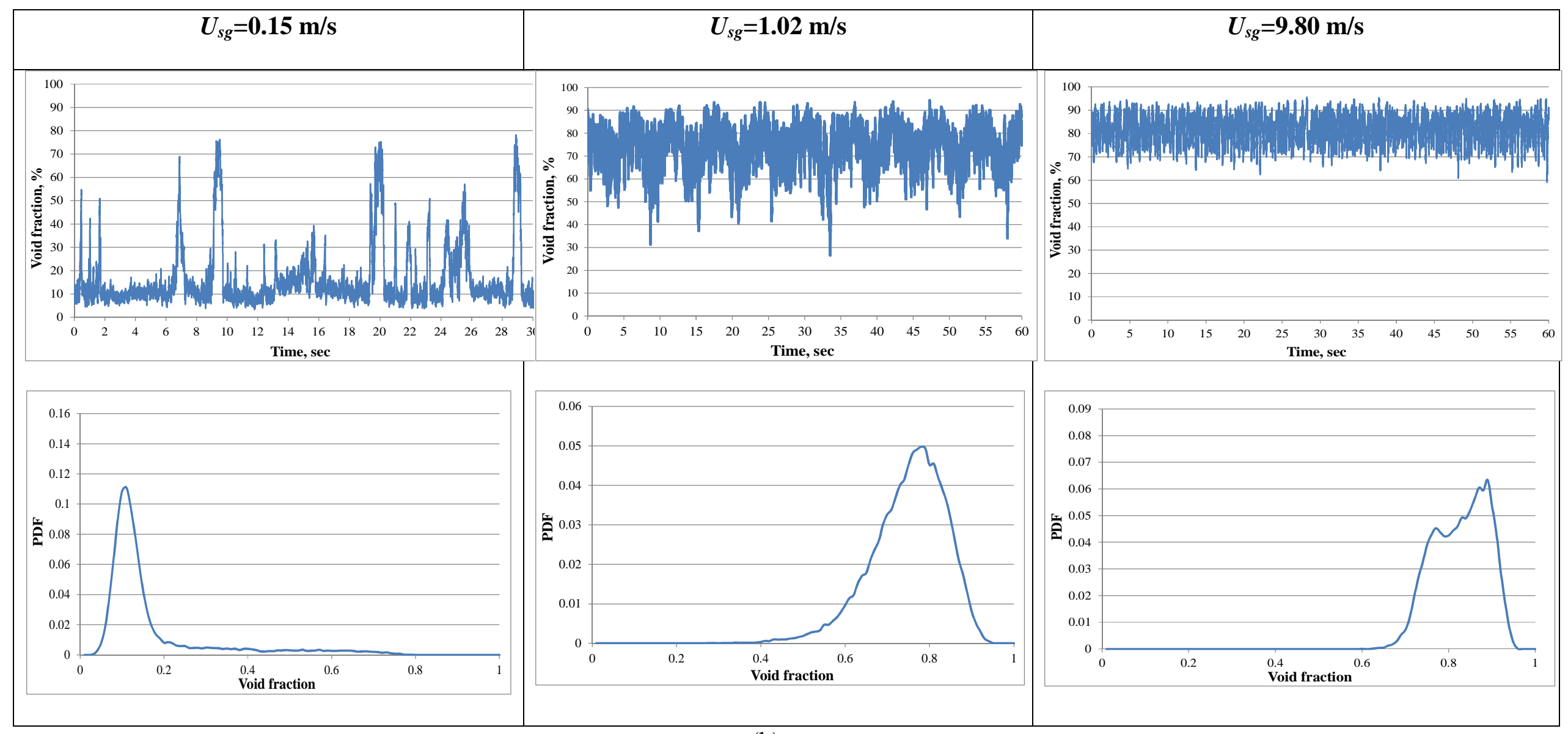

(b) 


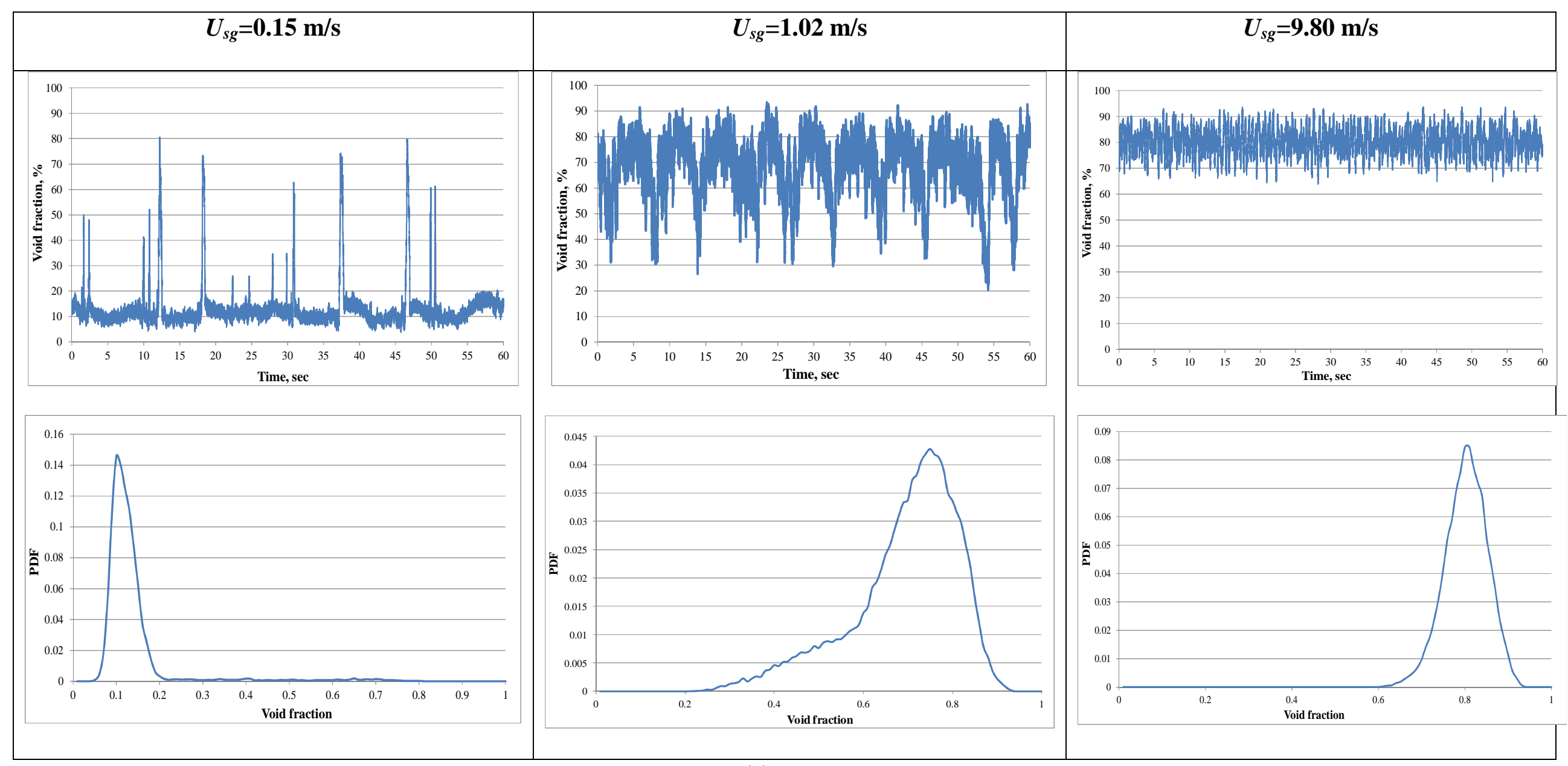

(c)

Figure 7: Time traces of the void fraction and their PDFs, at the (a) top, (b) middle and (c) bottom positions of downward section at different superficial air velocities $\left(U_{s g}\right)$ and a fixed superficial water velocity $\left(U_{s l}\right)$ of $1.0 \mathrm{~m} / \mathrm{s}$. 


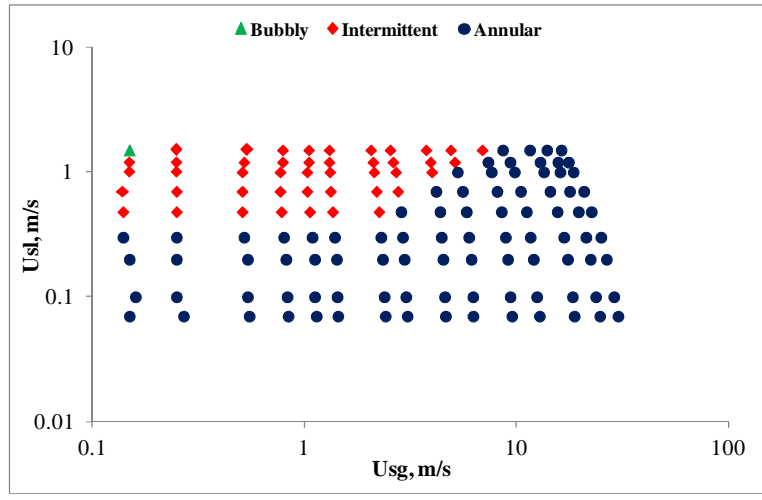

(a) Top position

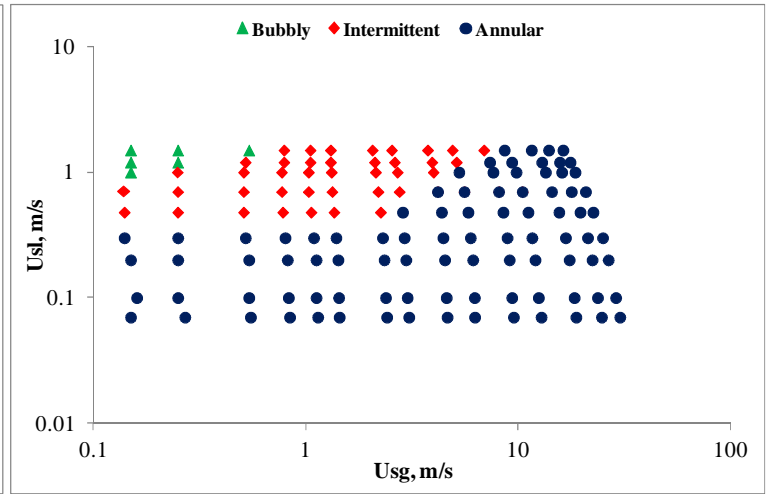

(b) Middle position

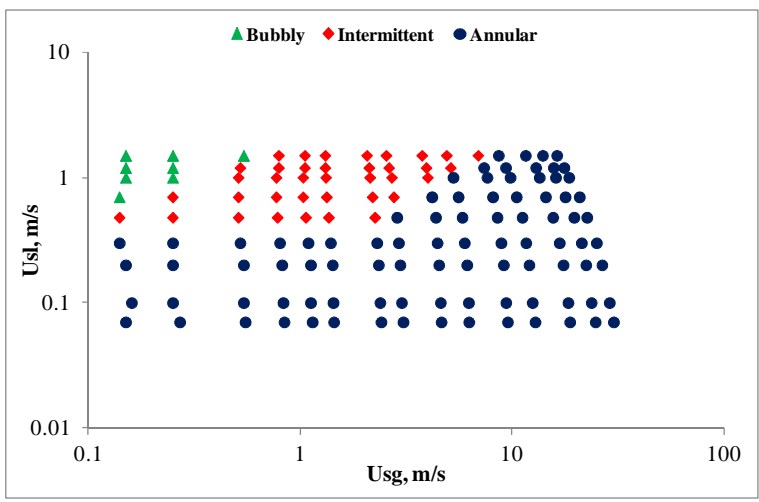

(c) Bottom position

Figure 8: Flow regime maps at the top, middle and bottom positions of the downward section, respectively. 


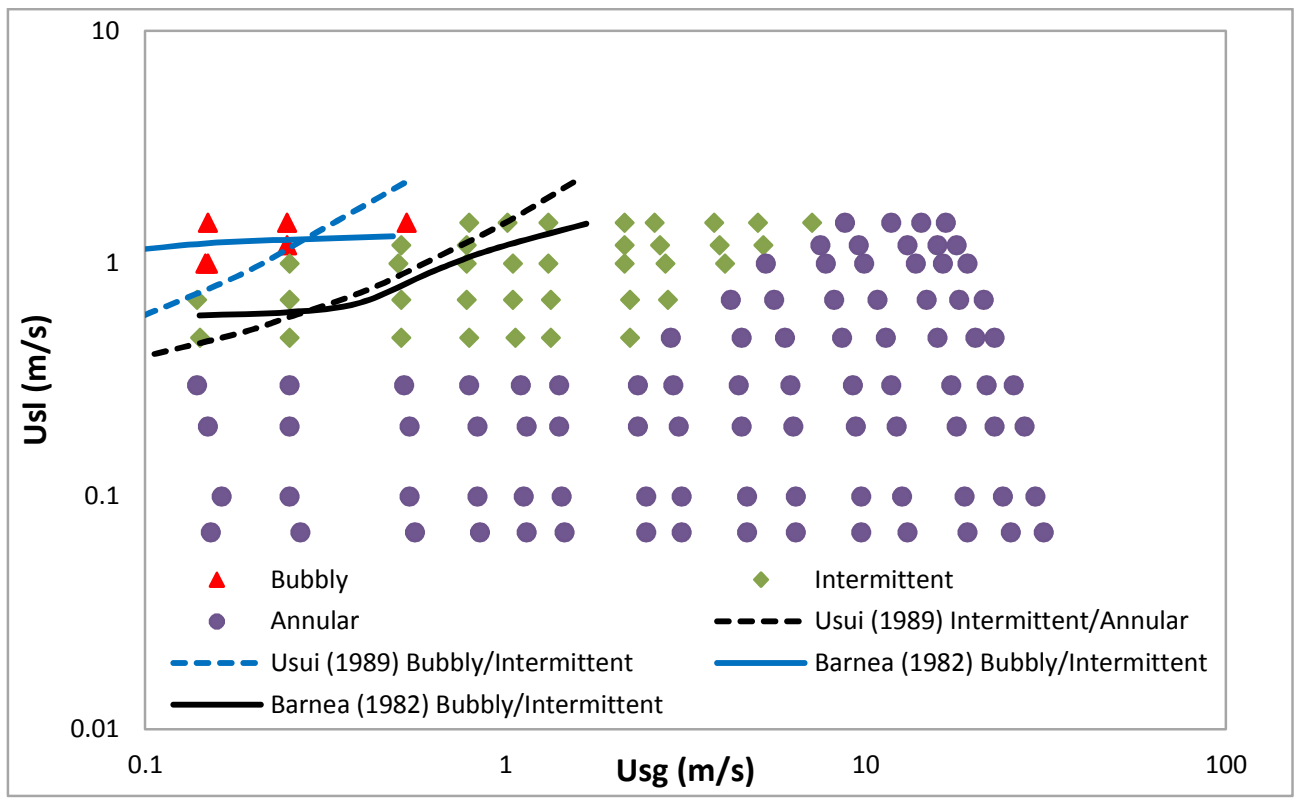

Figure 9: The comparison between the flow regime map at the middle position of the downward section obtained from this study and the flow regime map by Barnea et al. (1982) and Usui (1989). 


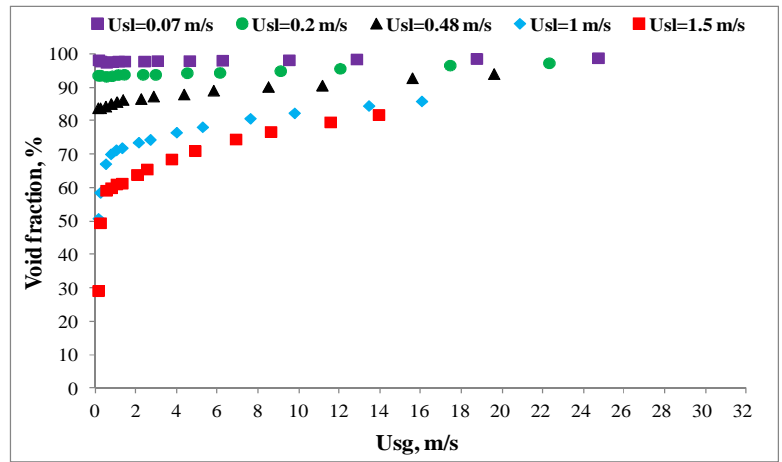

(a) Top position

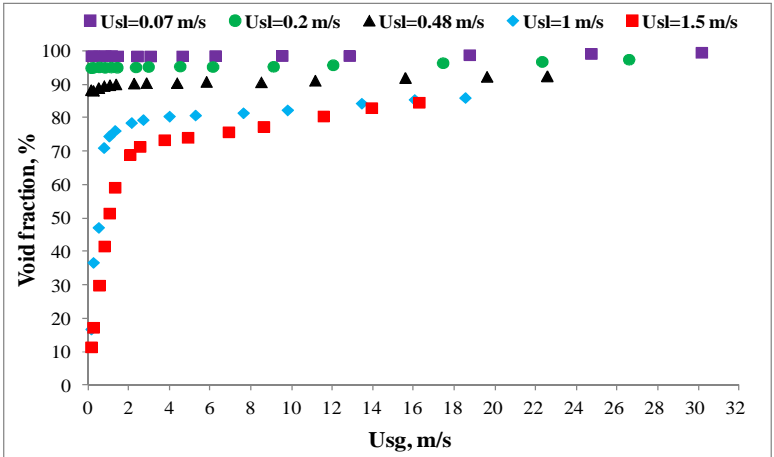

(b) Middle position

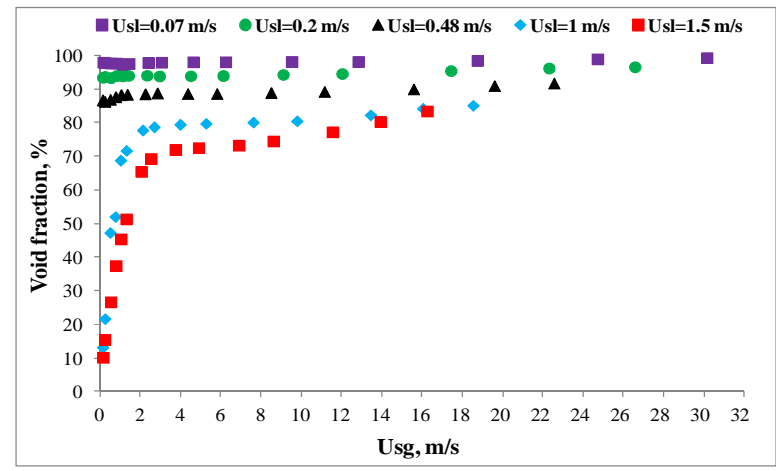

(c) Bottom position

Figure 10: The effect of the superficial air and water velocities on the void fraction values at the top, middle and bottom positions of the downward section, respectively. 


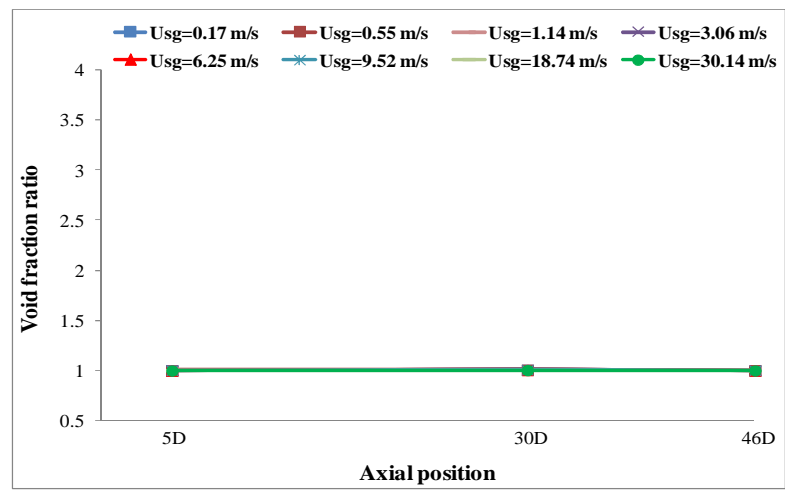

(a) $U_{s l}=0.07 \mathrm{~m} / \mathrm{s}$

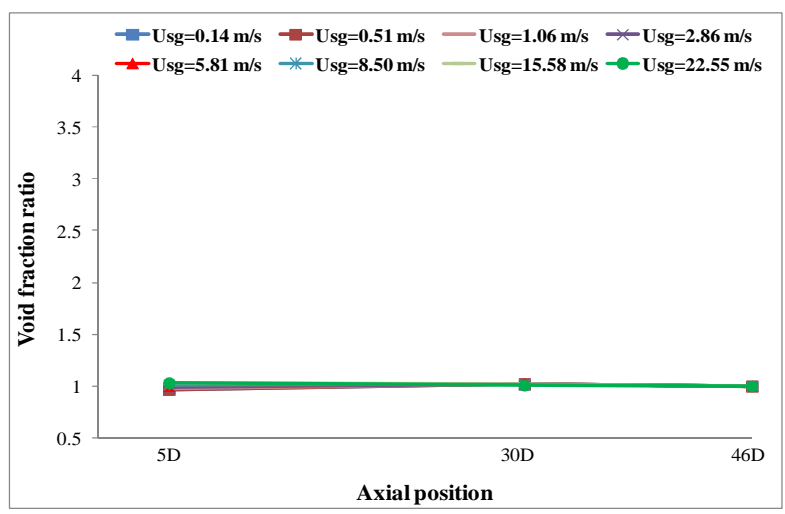

(c) $U_{s l}=0.48 \mathrm{~m} / \mathrm{s}$

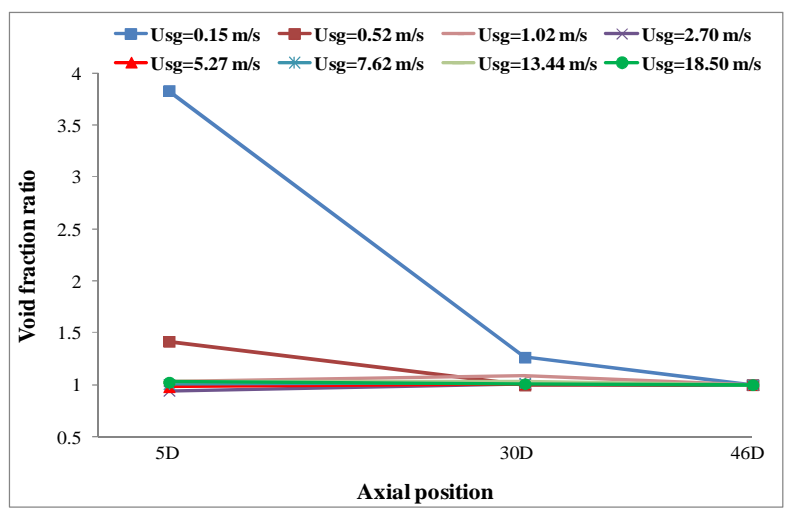

(e) $U_{s l}=1.0 \mathrm{~m} / \mathrm{s}$

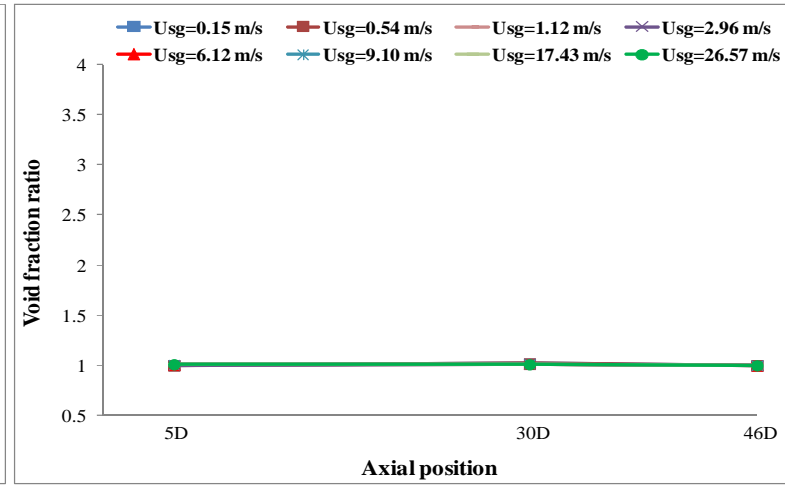

(b) $U_{s l}=0.2 \mathrm{~m} / \mathrm{s}$

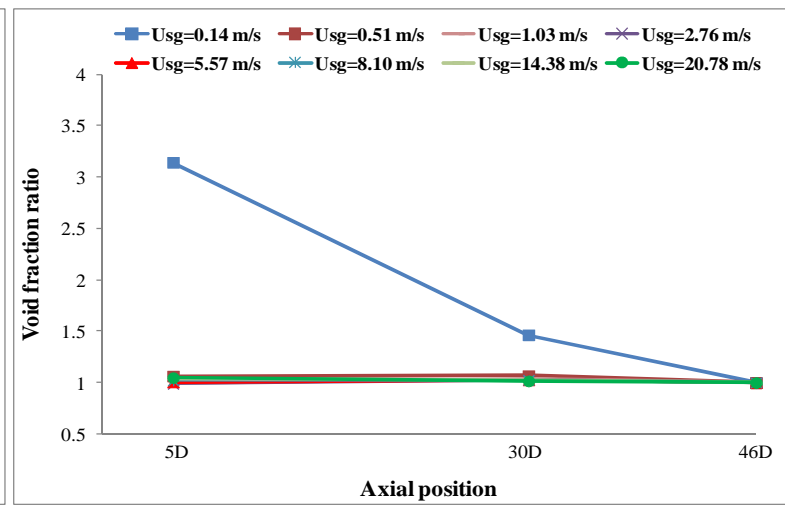

(d) $U_{s l}=0.7 \mathrm{~m} / \mathrm{s}$

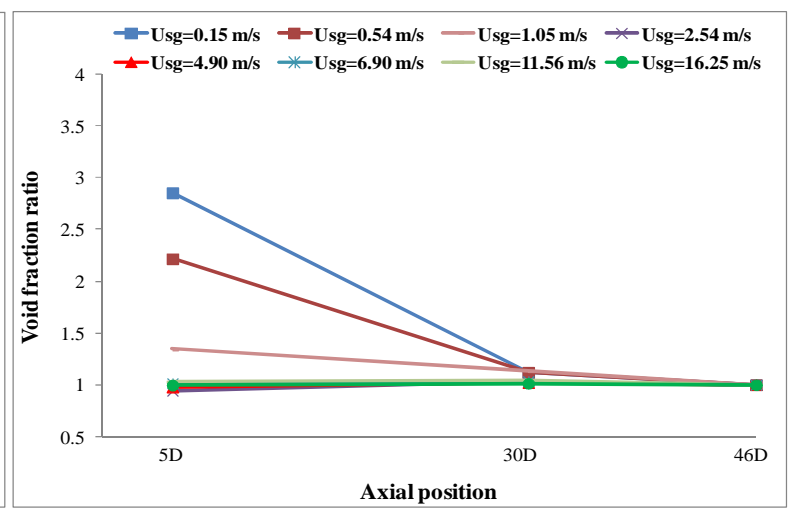

(f) $U_{s l}=1.5 \mathrm{~m} / \mathrm{s}$

Figure 11: The void fraction development along the downward section, for superficial water velocities of $0.07,0.2,0.48,1.0$ and $1.5 \mathrm{~m} / \mathrm{s}$, respectively. 


$$
U_{s g}=0.15 \mathrm{~m} / \mathrm{s}
$$

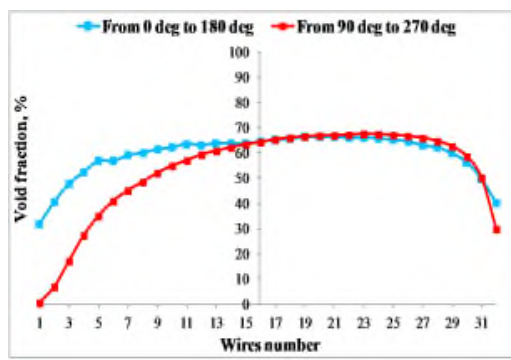

(a)

Void fraction, $\%$ $=0-20=20-40=40-60=60-80$

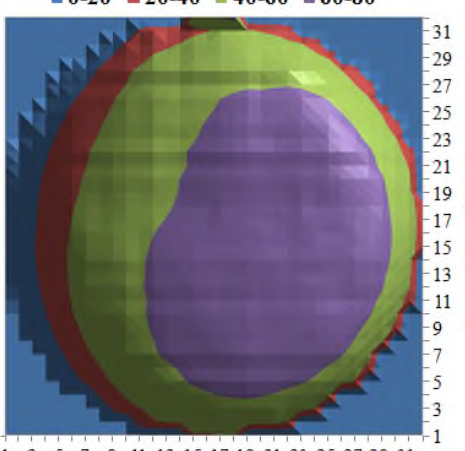

1357991113151719212325272931 From 90 to $270 \mathrm{deg}$

(b)

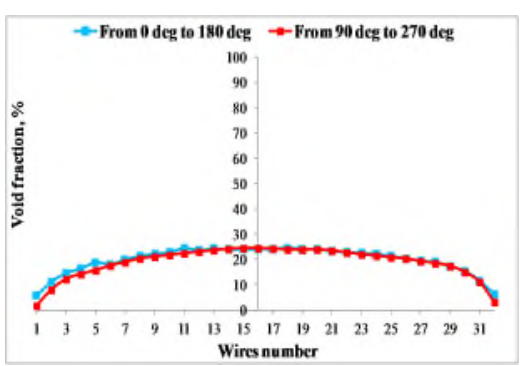

(a)

Void fraction, \% = $0-5=5-10=10-15=15-20=20-25$

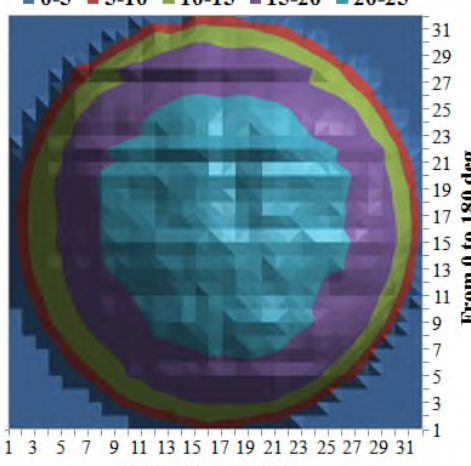

From 90 to $270 \mathrm{deg}$

(b)
$U_{s g}=1.02 \mathrm{~m} / \mathrm{s}$

$U_{s g}=9.80 \mathrm{~m} / \mathrm{s}$

\section{Top position}

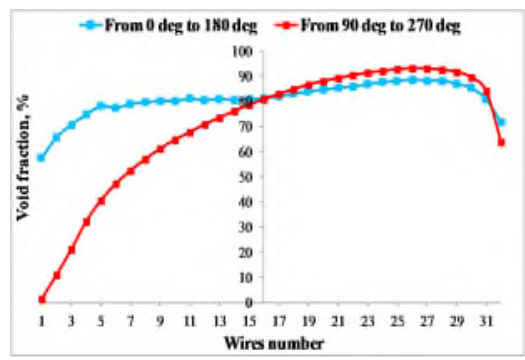

(a)

Void fraction, $\%$

$=0-20=20-40=40-60=60-80=80-100$

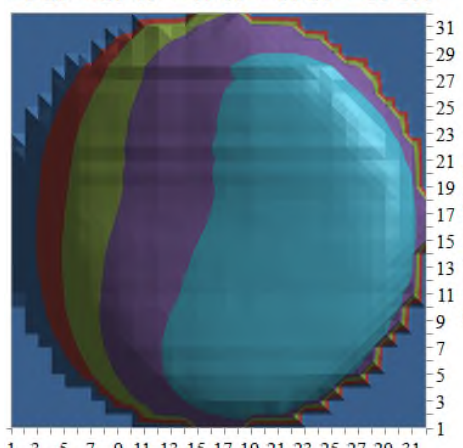

11131517192123

(b)

\section{Middle position}

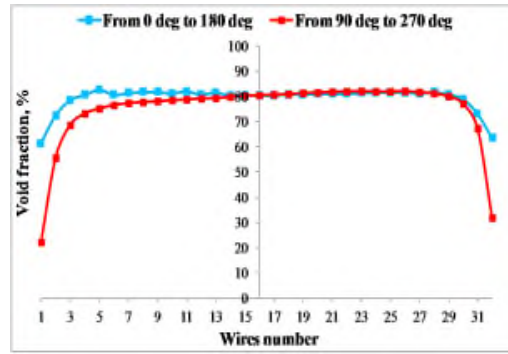

(a)

Void fraction, $\%$

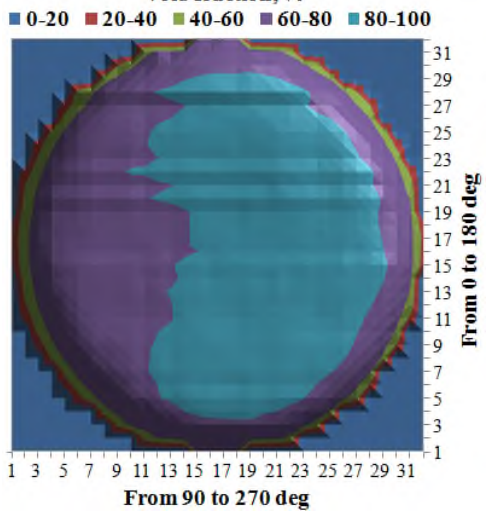

(b)

Void fraction, $\%$

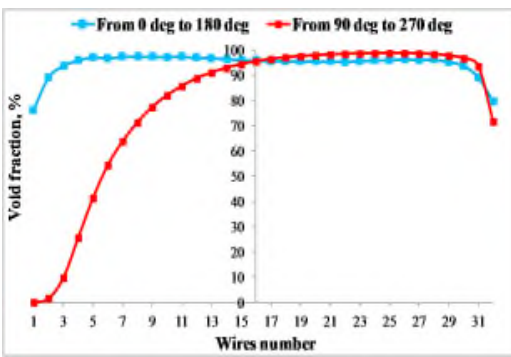

(a)

$0-20=20-40=40-60=60-80=80-100$

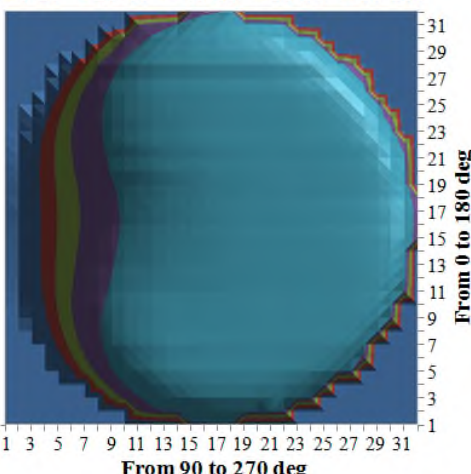

(b)

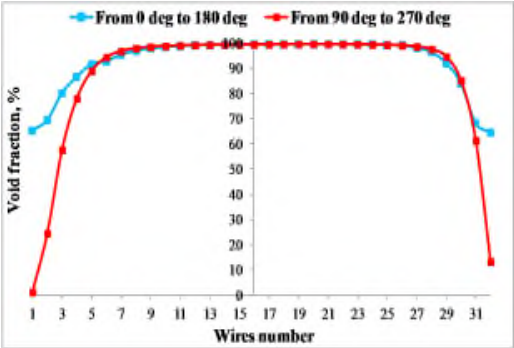

(a)

Void fraction, $\%$

= $0-20=20-40=40-60=60-80=80-100$

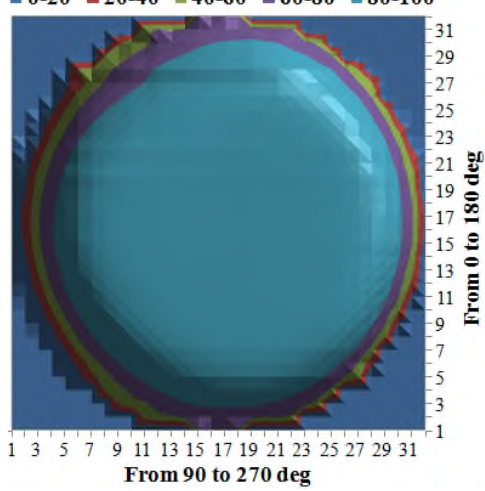

(b) 


\section{Bottom position}

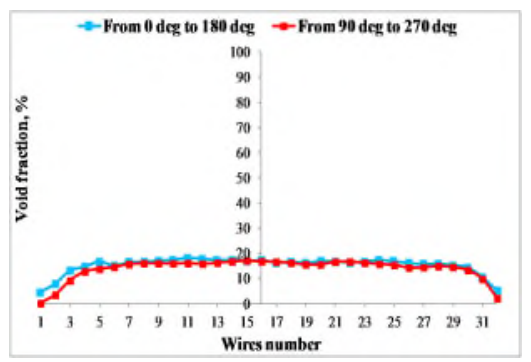

(a)

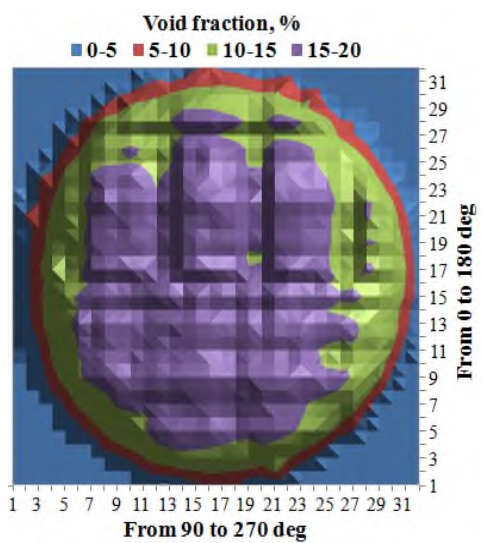

(b)

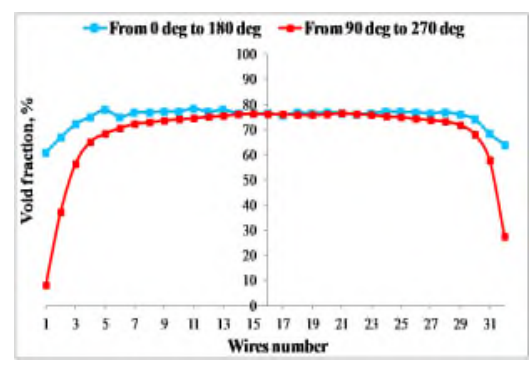

(a)

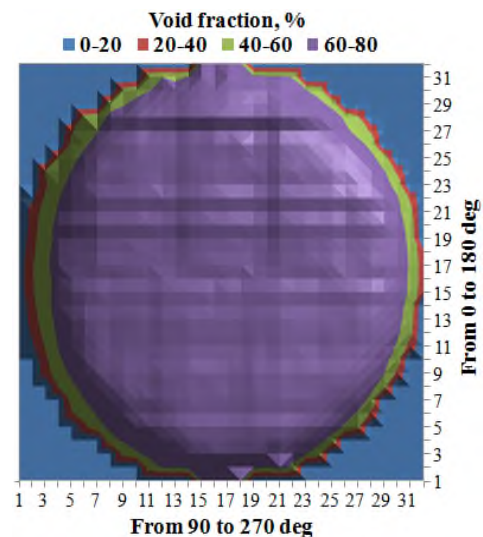

(b)

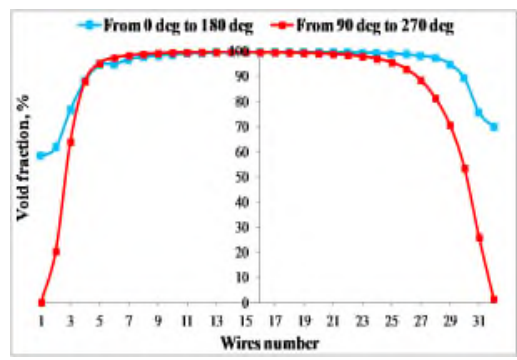

(a)

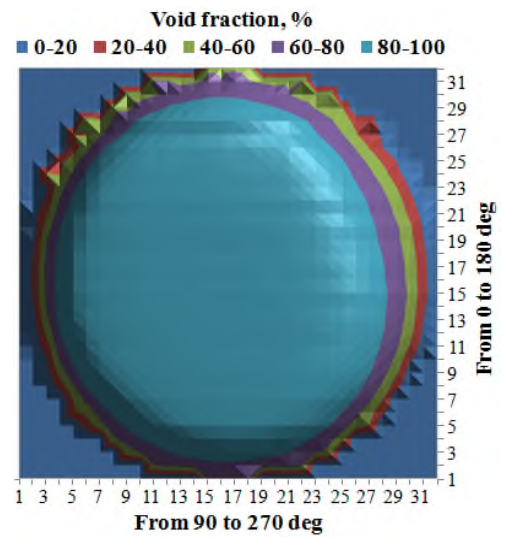

(b)

Figure 12: Chordal distributions (a) and contour plots (b) of the void fraction, at the top, middle and bottom positions of the downward section at different superficial air velocities $\left(U_{s g}\right)$ and a fixed superficial water velocity $\left(U_{s l}\right)$ of $1.0 \mathrm{~m} / \mathrm{s}$. 

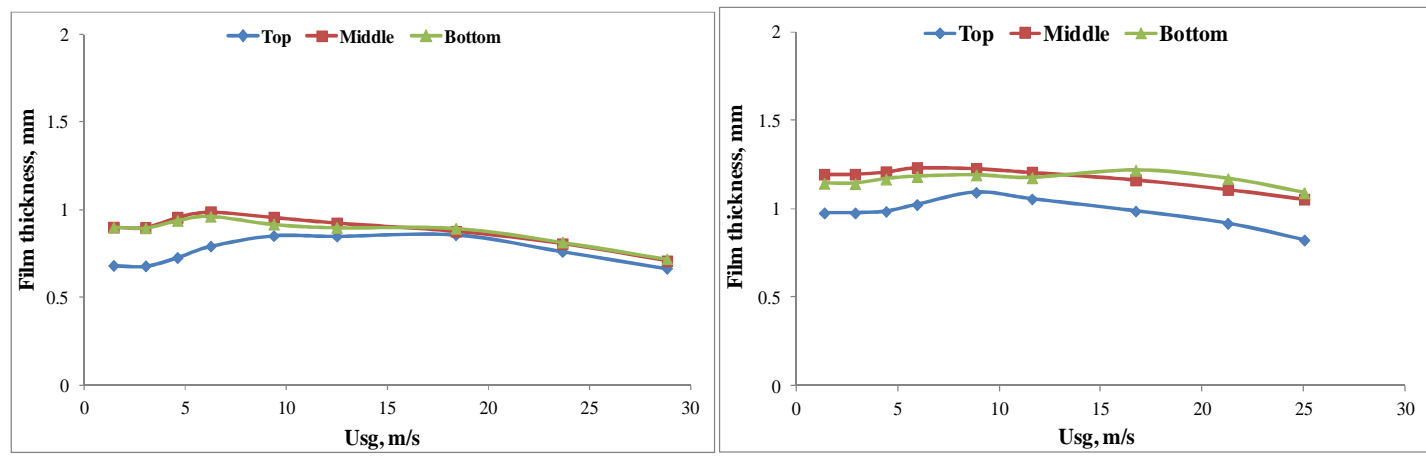

(a) $U_{s l}=0.1 \mathrm{~m} / \mathrm{s}$

(b) $U_{s l}=0.3 \mathrm{~m} / \mathrm{s}$

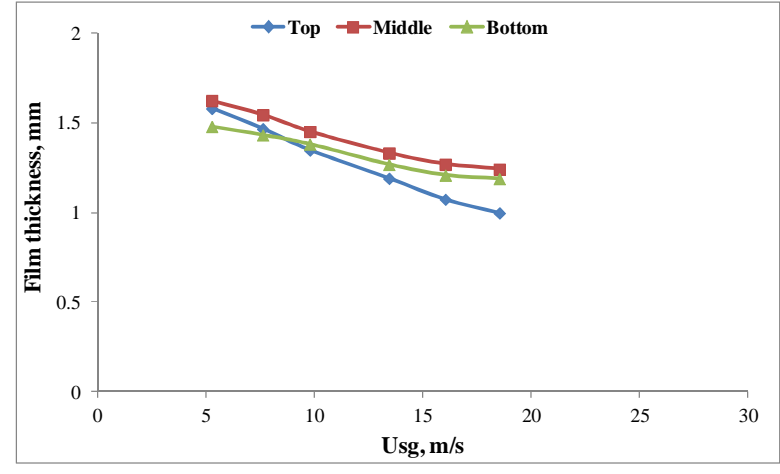

(c) $U_{s l}=1.0 \mathrm{~m} / \mathrm{s}$

Figure 13: Development of average film thickness in downward section 


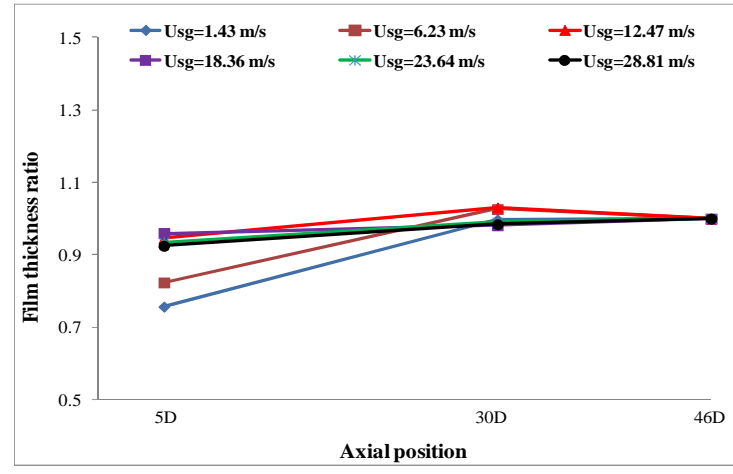

(a) $U_{s l}=0.1 \mathrm{~m} / \mathrm{s}$

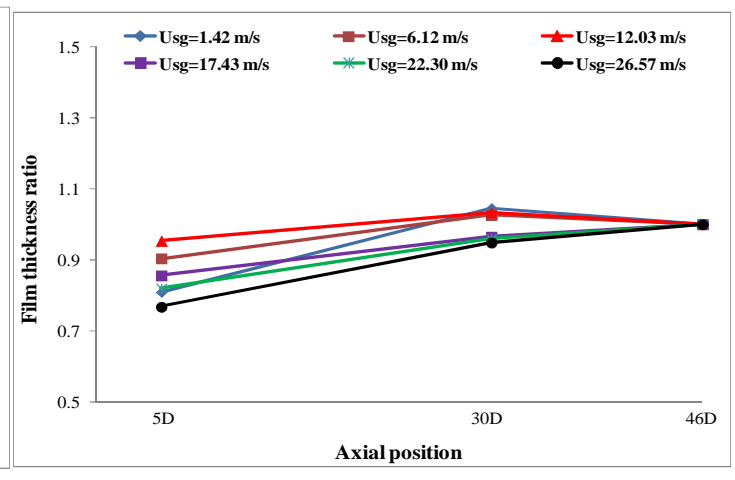

(b) $U_{s l}=0.2 \mathrm{~m} / \mathrm{s}$

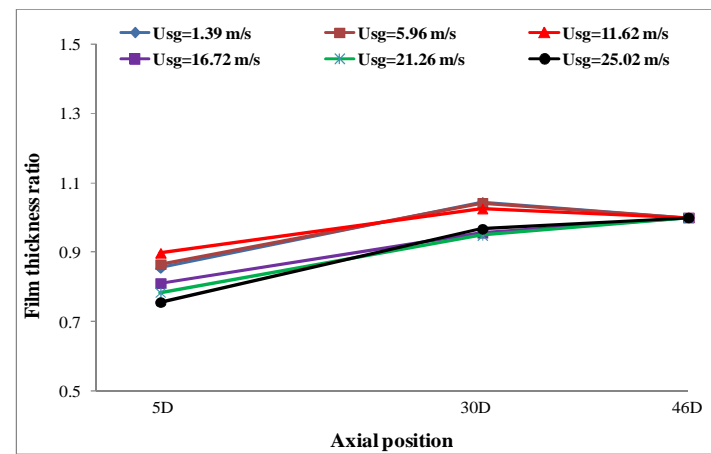

(c) $U_{s l}=0.3 \mathrm{~m} / \mathrm{s}$

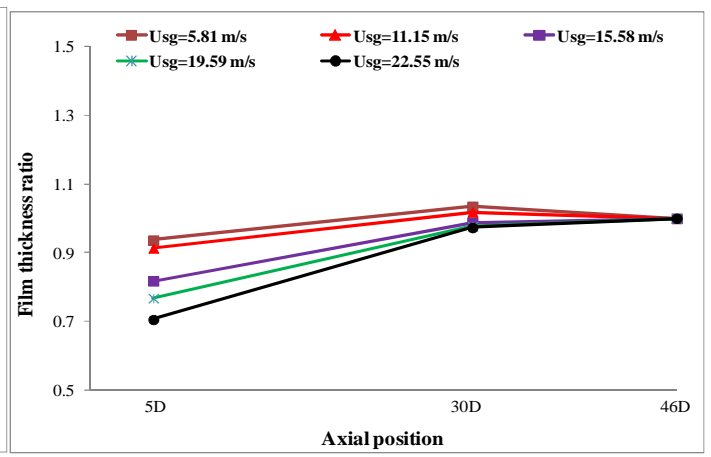

(d) $U_{s l}=0.48 \mathrm{~m} / \mathrm{s}$

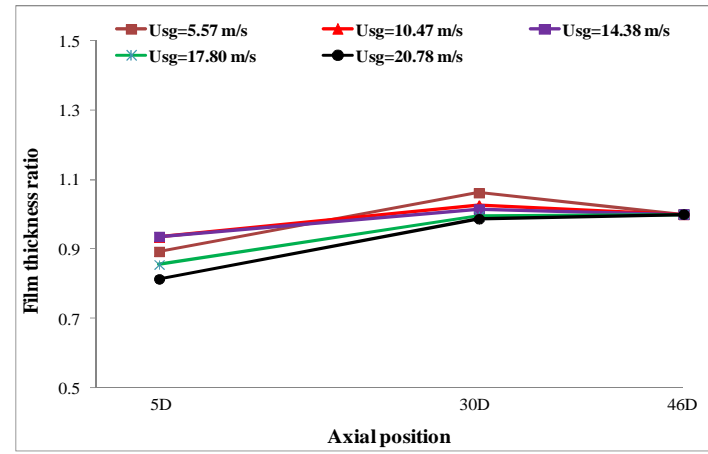

(e) $U_{s l}=0.7 \mathrm{~m} / \mathrm{s}$

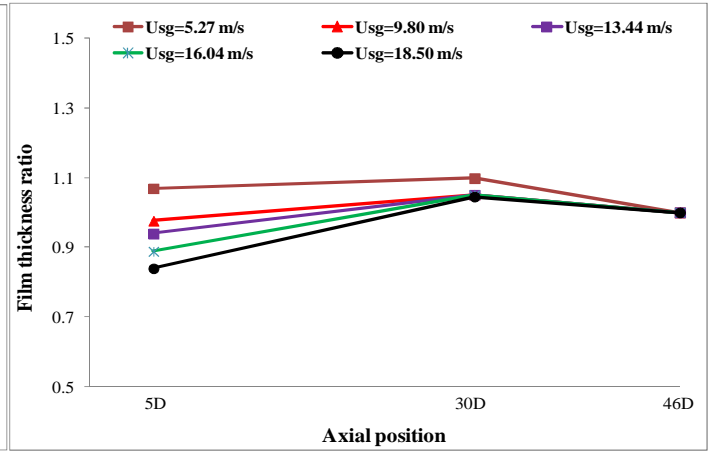

(f) $U_{s l}=1.0 \mathrm{~m} / \mathrm{s}$

Figure 14: The liquid film development along the downward section, for superficial water velocities $\left(U_{s l}\right)$ of $0.1,0.2,0.48,0.7$ and $1.0 \mathrm{~m} / \mathrm{s}$. 


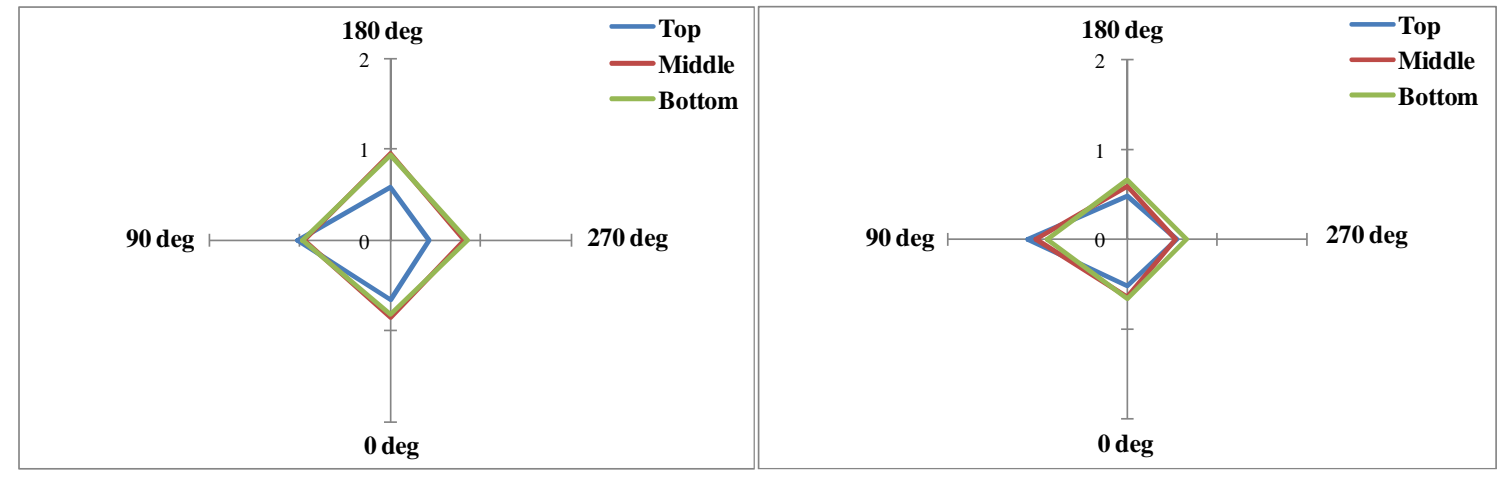

(a) $U_{s g}=3.0 \mathrm{~m} / \mathrm{s}$

(b) $U_{s g}=28.8 \mathrm{~m} / \mathrm{s}$

Figure 15: Circumferential profile developments of liquid film in downward section $\left(U_{s l}=\right.$ $0.1 \mathrm{~m} / \mathrm{s}$; axis unit in all plots: $\mathrm{mm}$ ). 


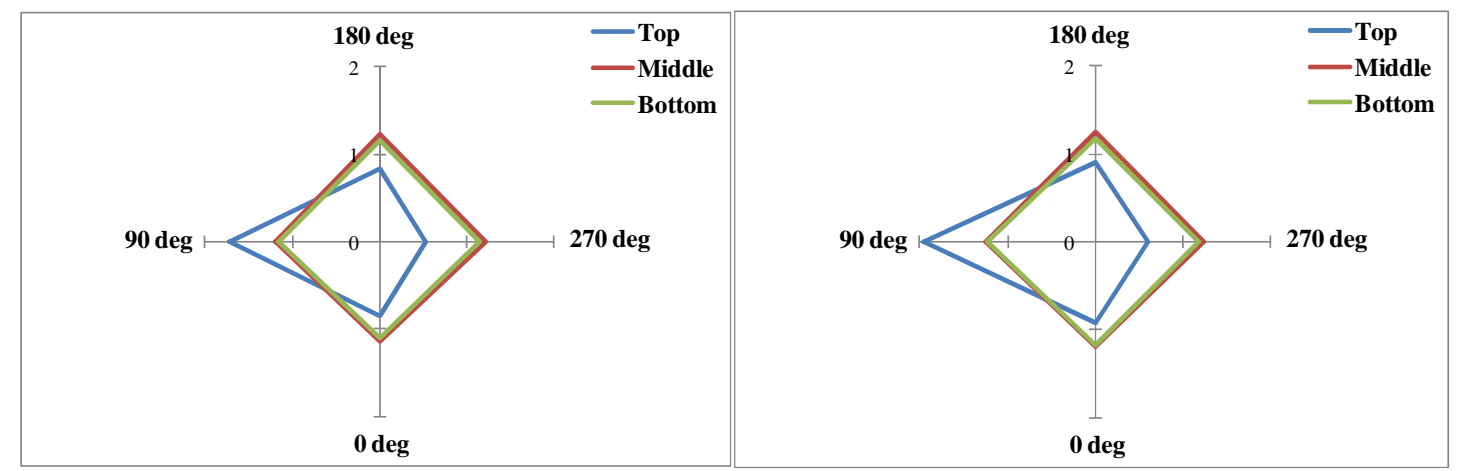

(a) $U_{s g}=2.90 \mathrm{~m} / \mathrm{s}$

(b) $U_{s g}=8.87 \mathrm{~m} / \mathrm{s}$

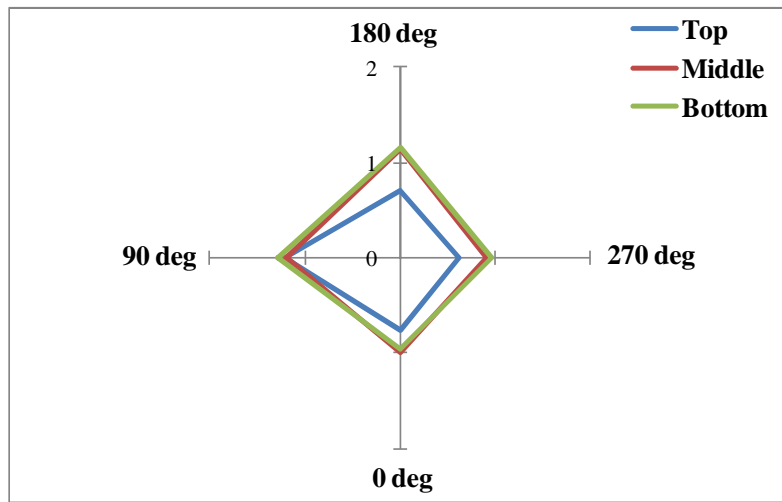

(c) $U_{s g}=25 \mathrm{~m} / \mathrm{s}$

Figure 16: Circumferential profile developments of liquid film in downward section $\left(U_{s l}=0.3 \mathrm{~m} / \mathrm{s}\right.$; axis unit in all plots: $\left.\mathrm{mm}\right)$ 


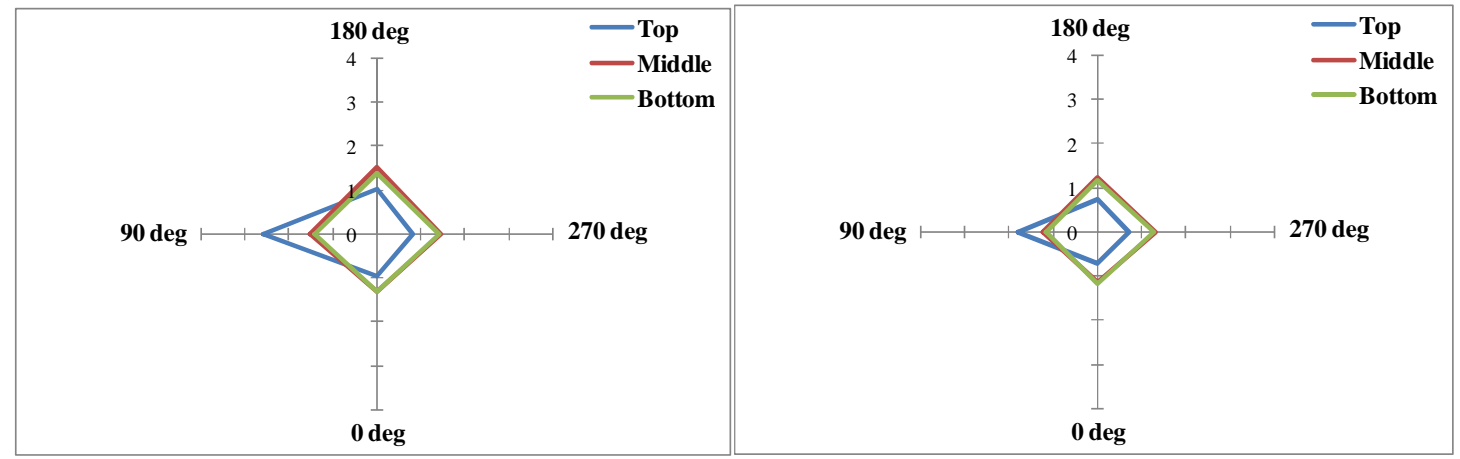
(a) $U_{s g}=9.80 \mathrm{~m} / \mathrm{s}$
(b) $U_{s g}=18.50 \mathrm{~m} / \mathrm{s}$

Figure 17: Circumferential profile developments of liquid film in downward section $\left(U_{s l}=1.0 \mathrm{~m} / \mathrm{s}\right.$; axis unit in all plots: $\left.\mathrm{mm}\right)$ 


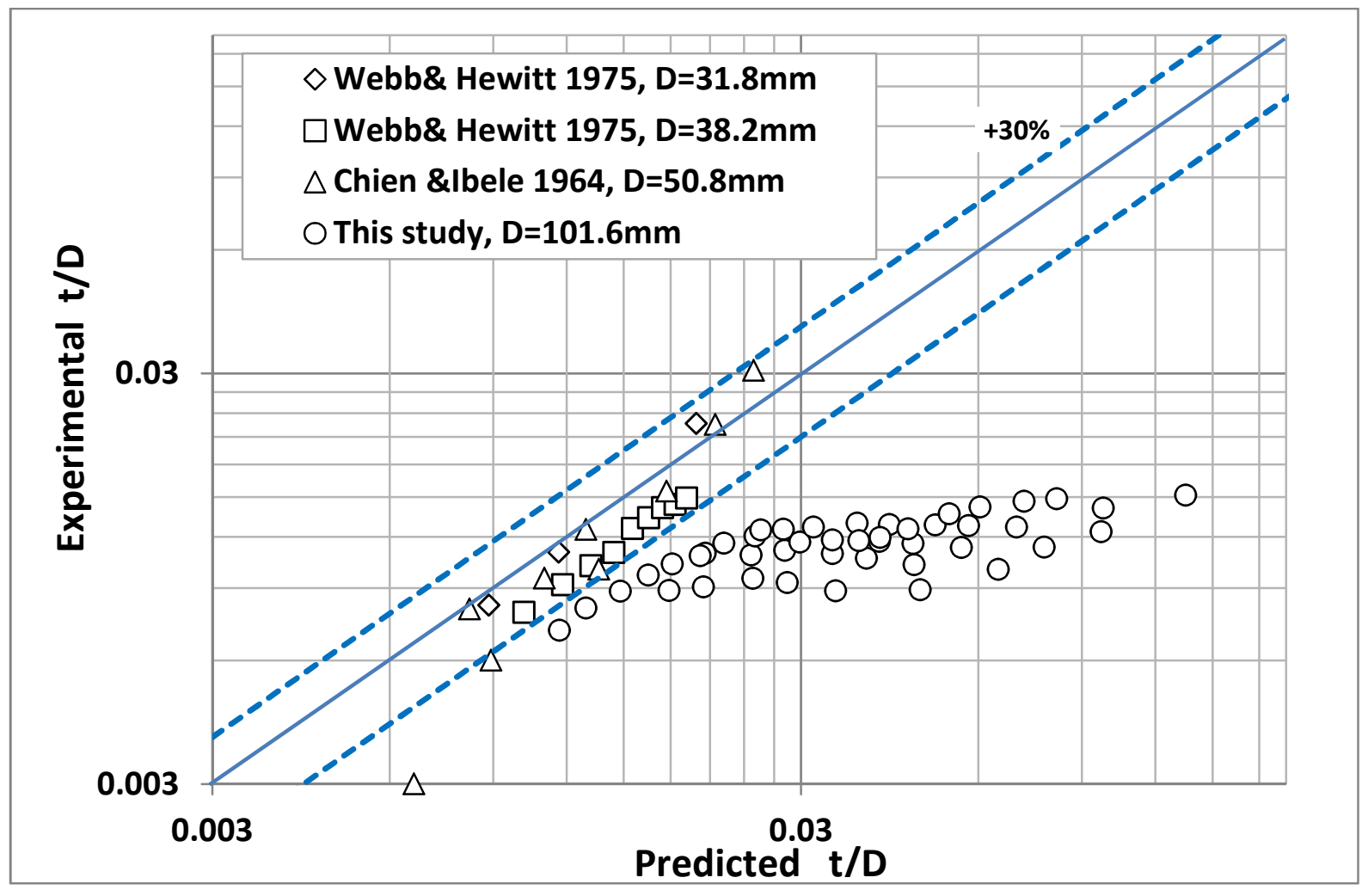

Figure 18 Comparison between the data sets of film thickness in downward annular flows in different size of pipes with the Henstock and Hanratty (1976) correlation 


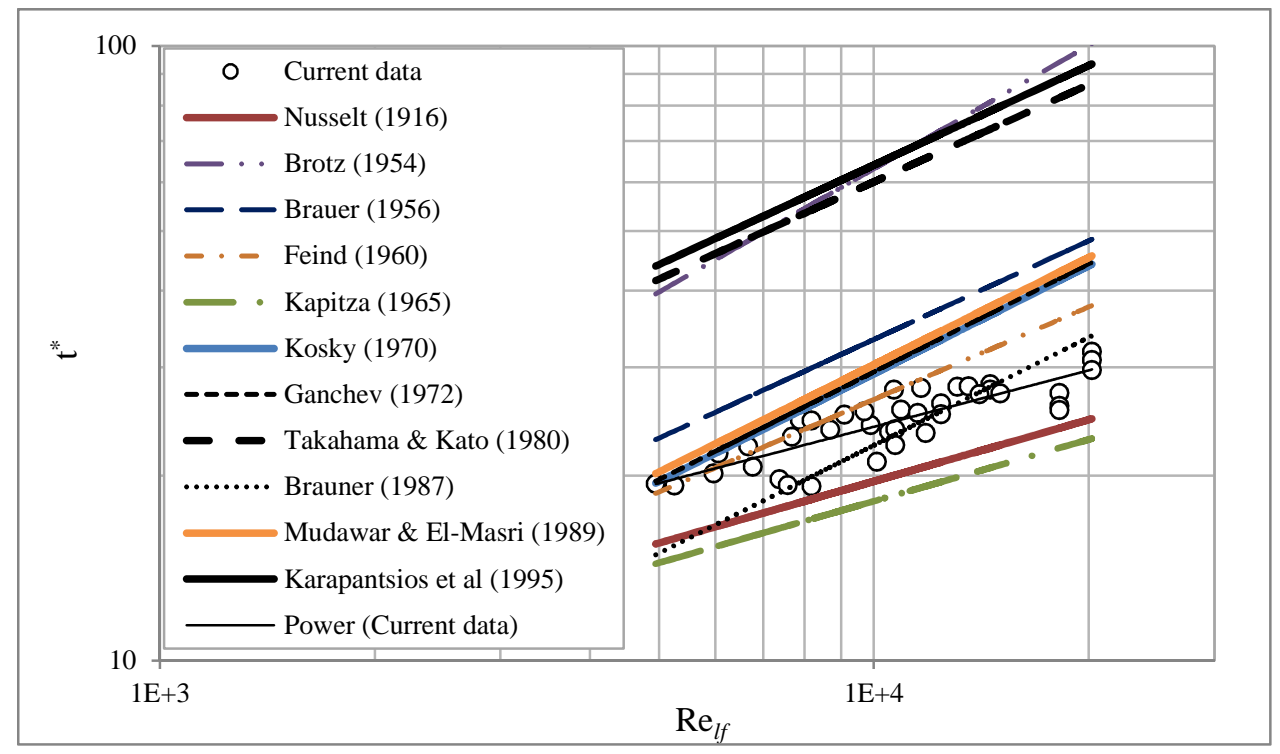

(a)

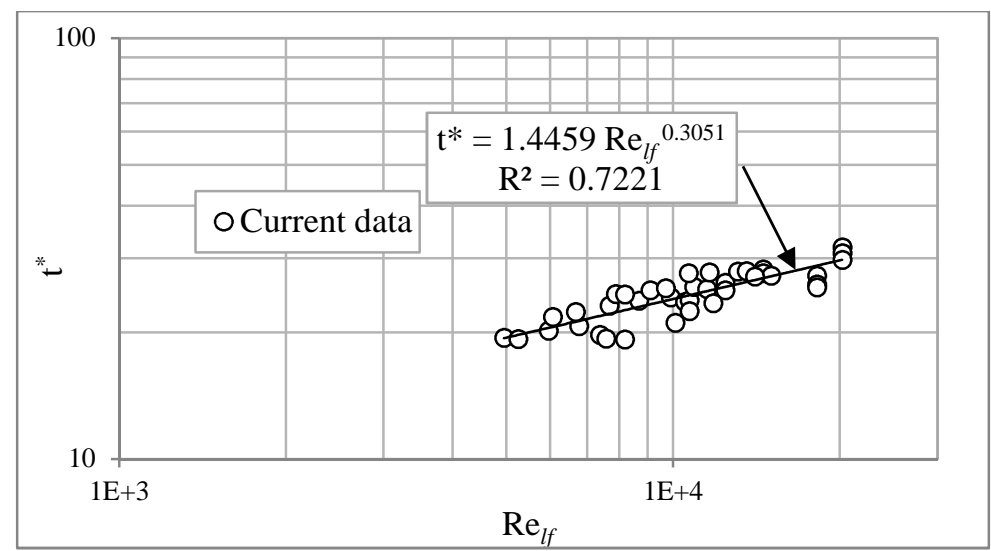

(b)

Figure 19: (a) Mean film thickness in falling film flow: comparing current experiments to existing models. Where $t^{*}=t\left(g / v_{l}^{2}\right)^{1 / 3}$ is the dimensionless film thickness and $R e_{l f}=$ $4 \dot{m}_{l} / \mu_{l}$ the liquid film Reynolds number (b) Fitted correlation of large pipe dimensioness film thickness 
Table 1: Locations of the sensors and observation stations along the test section

\begin{tabular}{|c|c|c|}
\hline Items & Locations (in tube inner diameter D) & Note \\
\hline MV11 & $5 \mathrm{D}$ from the end of bend 1 & \multirow{3}{*}{$\begin{array}{l}\text { Downward section, } \\
\text { downstream of bend } 1\end{array}$} \\
\hline MV12 & $30 \mathrm{D}$ from the end of bend 1 & \\
\hline MV13 & $46 \mathrm{D}$ from the end of bend 1 & \\
\hline MV21 & $5 \mathrm{D}$ from the end of bend 2 & \multirow{3}{*}{$\begin{array}{l}\text { Upward section, } \\
\text { downstream of bend } 2\end{array}$} \\
\hline MV22 & $28 \mathrm{D}$ from the end of bend 2 & \\
\hline MV23 & 47D from the end of bend 2 & \\
\hline $\mathrm{P} 1$ & 10D upstream of the beginning of bend 1 & \\
\hline $\mathrm{P} 2$ & 10D downstream of the end of bend 1 & \multirow{4}{*}{$\begin{array}{l}\text { Downward section, } \\
\text { downstream of bend1 } \\
\text { Upward section, } \\
\text { downstream of bend } 2\end{array}$} \\
\hline P3 & 50D downstream of the end of bend 1 & \\
\hline $\mathrm{P} 4$ & 10D downstream of the end of bend 2 & \\
\hline P5 & 50D downstream of the end of bend 2 & \\
\hline P6 & 10D downstream of the end of bend 3 & \multirow{3}{*}{$\begin{array}{l}\text { For water temperature } \\
\text { measurement } \\
\text { For water/air mixture } \\
\text { temperature measurement }\end{array}$} \\
\hline $\mathrm{T} 1$ & In the water line before the mixer & \\
\hline $\mathrm{T} 2$ & At the exit of the test section & \\
\hline
\end{tabular}

Table 2: Sources of film thickness data from downward air/water annular flows

\begin{tabular}{|c|c|c|c|c|c|}
\hline No & Source & $\begin{array}{l}\text { Pipe diameter D } \\
\qquad(\mathrm{mm})\end{array}$ & $\begin{array}{l}\text { Distance from the } \\
\text { inject/bend } \\
\text { (times D) }\end{array}$ & $\begin{array}{l}\text { Water } \\
\text { Reynolds } \\
\text { Number }\end{array}$ & $\begin{array}{c}\text { Air } \\
\text { Reynolds } \\
\text { Number }\end{array}$ \\
\hline 1 & $\begin{array}{c}\text { Webb \& Hewitt } \\
(1975)\end{array}$ & 31.8 & Not available & $500-4000$ & 50500 \\
\hline 2 & $\begin{array}{c}\text { Webb \& Hewitt } \\
\text { (1975) }\end{array}$ & 38.2 & $>140$ & $840-4200$ & 42100 \\
\hline 3 & $\begin{array}{c}\text { Chien \& Ibele } \\
1964\end{array}$ & 50.8 & 88 & $\begin{array}{l}1150- \\
15100\end{array}$ & $\begin{array}{l}28000- \\
260000\end{array}$ \\
\hline 4 & This study & 101.6 & 46 & $\begin{array}{l}10100- \\
101000\end{array}$ & $\begin{array}{l}12000- \\
205000\end{array}$ \\
\hline
\end{tabular}

Table 3: Some falling film relations and flow conditions

\begin{tabular}{lllll}
\hline Researchers & $A$ & $n$ & Basis of model & Geometry/flow conditions \\
\hline Brotz (1954) & 0.161 & $2 / 3$ & Empirical & Pipe/ $R e_{l f}=100-4300$ \\
Brauer (1956) & 0.245 & $8 / 15$ & Empirical & Not available \\
\hline
\end{tabular}




\begin{tabular}{|c|c|c|c|c|}
\hline Fiend (1960) & 0.532 & $1 / 2$ & Empirical & Not available \\
\hline Kapitza (1965) & 0.843 & $1 / 3$ & Theoretical & Not available \\
\hline Kosky (1971) & 0.136 & $7 / 12$ & Semi-empirical & $\mathrm{Pipe} / R e_{l f}>1000$ \\
\hline Ganchev et al. (1972) & 0.137 & $7 / 12$ & Theoretical & Not available \\
\hline $\begin{array}{l}\text { Takahama and Kato } \\
\text { (1980) }\end{array}$ & 0.473 & 0.526 & Empirical & Pipe/Re $e_{l f}<8000$ \\
\hline Brauner (1987) & 0.104 & $7 / 12$ & Theoretical & Flat plate $/ R e_{l f}>300$ \\
\hline $\begin{array}{l}\text { Mudawar and El-Masri } \\
\text { (1988) }\end{array}$ & 0.145 & 0.58 & Theoretical & Pipe, $R e_{l f}<10000$ \\
\hline $\begin{array}{l}\text { Karapantsios and } \\
\text { Karabelas (1995) }\end{array}$ & 0.451 & 0.538 & Empirical & Pipe, $R e_{l f}=370-11080$ \\
\hline
\end{tabular}

Table A-1 Flow conditions used throughout this study

$\left(\mathrm{Qg}, U_{s g}\right.$ and $U_{s l}$ are air flow rates, superficial air velocities and superficial water velocities respectively)

\begin{tabular}{|c|c|c|c|c|c|c|c|c|c|}
\hline$U_{s l}, \mathbf{m} / \mathbf{s}$ & 0.07 & 0.1 & 0.2 & 0.3 & 0.48 & 0.7 & 1.0 & 1.2 & 1.5 \\
\hline Qg, & $U_{s g}$ & $U_{s g}$ & $U_{s g}$ & $U_{s g}$ & $U_{s g}$ & $U_{s g}$ & $U_{s g}$, & $U_{s g}$ & $U_{s g}$, \\
\hline $\mathrm{Sm}^{3} / \mathrm{h}$ & $\mathbf{m} / \mathbf{s}$ & $\mathbf{m} / \mathbf{s}$ & $\mathbf{m} / \mathbf{s}$ & $\mathbf{m} / \mathbf{s}$ & $\mathbf{m} / \mathbf{s}$ & $\mathbf{m} / \mathbf{s}$ & $\mathbf{m} / \mathbf{s}$ & $\mathbf{m} / \mathbf{s}$ & $\mathbf{m} / \mathbf{s}$ \\
\hline 6 & 0.15 & 0.16 & 0.15 & 0.14 & 0.14 & 0.14 & 0.15 & 0.15 & 0.15 \\
\hline 10 & 0.27 & 0.25 & 0.25 & 0.25 & 0.25 & 0.25 & 0.25 & 0.25 & 0.25 \\
\hline 20 & 0.55 & 0.54 & 0.54 & 0.52 & 0.51 & 0.51 & 0.52 & 0.52 & 0.54 \\
\hline 30 & 0.84 & 0.83 & 0.82 & 0.80 & 0.78 & 0.77 & 0.77 & 0.79 & 0.79 \\
\hline 40 & 1.14 & 1.12 & 1.12 & 1.09 & 1.06 & 1.03 & 1.02 & 1.05 & 1.05 \\
\hline 50 & 1.44 & 1.43 & 1.42 & 1.39 & 1.36 & 1.33 & 1.32 & 1.31 & 1.31 \\
\hline 80 & 2.41 & 2.38 & 2.34 & 2.30 & 2.25 & 2.19 & 2.13 & 2.11 & 2.06 \\
\hline 100 & 3.06 & 3.01 & 2.96 & 2.91 & 2.86 & 2.76 & 2.70 & 2.62 & 2.54 \\
\hline 150 & 4.63 & 4.59 & 4.51 & 4.43 & 4.36 & 4.18 & 3.99 & 3.93 & 3.75 \\
\hline 200 & 6.25 & 6.23 & 6.12 & 5.96 & 5.81 & 5.57 & 5.27 & 5.12 & 4.90 \\
\hline 300 & 9.52 & 9.35 & 9.10 & 8.87 & 8.50 & 8.10 & 7.62 & 7.35 & 6.90 \\
\hline 400 & 12.84 & 12.47 & 12.03 & 11.62 & 11.15 & 10.47 & 9.80 & 9.33 & 8.62 \\
\hline
\end{tabular}




\begin{tabular}{|c|c|c|c|c|c|c|c|c|c|}
\hline 600 & 18.74 & 18.36 & 17.43 & 16.72 & 15.58 & 14.38 & 13.44 & 12.94 & 11.56 \\
\hline 800 & 24.71 & 23.64 & 22.30 & 21.26 & 19.59 & 17.80 & 16.04 & 15.67 & 13.92 \\
\hline 1000 & 30.14 & 28.81 & 26.57 & 25.02 & 22.55 & 20.78 & 18.53 & 17.58 & 16.25 \\
\hline
\end{tabular}

Table A-2 Summary of instruments installed on the Serpent rig

\begin{tabular}{|c|c|c|c|c|}
\hline Instruments & Name & Manufacture \& Model & Uncertainty & Range \\
\hline $\begin{array}{l}\text { Air flow } \\
\text { meter } 1\end{array}$ & FA1 & $\begin{array}{c}\text { Rosemount Mass } \\
\text { Probar 1/2, }\end{array}$ & $0.5 \%$ & $0-150 \mathrm{Sm}^{3} / \mathrm{h}$ \\
\hline $\begin{array}{l}\text { Air flow } \\
\text { meter } 2\end{array}$ & FA2 & $\begin{array}{c}\text { Rosemount Mass } \\
\text { Probar 1', }\end{array}$ & $0.5 \%$ & $150-4250 \mathrm{Sm}^{3} / \mathrm{h}$ \\
\hline $\begin{array}{c}\text { Water flow } \\
\text { meter }\end{array}$ & FW & ABB MMSG-Special & $0.1 \%$ & $0.06-16 \mathrm{l} / \mathrm{s}$ \\
\hline $\begin{array}{l}\text { Pressure } \\
\text { sensors }\end{array}$ & P1-6 & GE Sensing PMP4070 & $0.08 \%$ & 0-100 psig \\
\hline $\begin{array}{c}\text { Temperature } \\
\text { sensors }\end{array}$ & $\mathrm{T} 1 / 2$ & Pt100 & $0.5 \%$ & $0-100 \mathrm{C}$ \\
\hline $\begin{array}{c}\text { Wire mesh } \\
\text { sensor }\end{array}$ & & $\begin{array}{l}\text { Helmholtz-Zentrum } \\
\text { Dresden-Rossendorf } \\
\text { (HZDR), CAP200 }\end{array}$ & $\begin{array}{c}\text { Wire spacing } \\
\qquad 3.2 \mathrm{~mm}\end{array}$ & $\begin{array}{l}\text { Void fraction: } \\
0-100 \%\end{array}$ \\
\hline $\begin{array}{l}\text { Liquid film } \\
\text { thickness } \\
\text { probes }\end{array}$ & FT1/2 & $\begin{array}{c}\text { Design and } \\
\text { manufactured by PSE } \\
\text { group, Cranfield }\end{array}$ & $0.1 \mathrm{~mm}$ & $0-3 \mathrm{~mm}$ \\
\hline
\end{tabular}

